\title{
The Determinants of Resistance to Change Management Process: The Case of CBE, Addis Ababa District
}

\section{Dr. Hiyab Gebretsadik Weldearegay}

\author{
General Director, Entoto and Surrounding Tourist Destination Development (ESTDD) Project \\ Addis Ababa, Ethiopia. \\ hiyabgebretsadik.gg@gmail.com
}

\begin{abstract}
In this paper, the determinants of resistance to organizational change are studied in view of the Kurt Lewin's three phase model of change management process. The coefficient of fifteen sources of resistance is the critical concerns of this study and are weighed against which aspect of sources of resistance presents a higher disparity of impact considering the phases of the change process as well as which has lower significance or/ and no significance at all. Questionnaires were distributed randomly to a sample of 150 in the 27 branches of Commercial Bank of Ethiopia found in Addis Ababa. A unidirectional logit regression of odds ratio and marginal function analysis was used to get a finding that age and gender are not predictors to resistance, while education and experience are negatively and positively predictors to resistance, respectively. It is also found that a single variable factor of resistance can have varied significance level on the unfreezing, moving and refreezing phases of a change process found by two way tables of column and row statistics with chi square measure of their association. In this regard vulnerability driven factor was the highest significant factor in the first two phases while managerial incapability driven factor in the last phase of change management process.
\end{abstract}

Keywords: Change Management, Resistance to Change, Organizational Behavior, Strategic Leadership, Logistic Regression

\section{INTRODUCTION}

\section{Background of the Study}

Nowadays, many literatures about organizational change like for example (Rumenet, 1995; Frankwick, 1995; Freeze, B.1998) make their introductory paragraph as an obligation to underscore change as a steady state of the contemporary organizations. This thesis is no exception. Organizations have to change to adapt to the new demands of their environments. But implementing change is so difficult that it is a miracle if it is enhanced easily. One major traced barrier for implementing change is resistance from employees, (Schein(19950)). Many psychological and management literature describe resistance as a normal or even natural psychological response to change, (Rumenet (1995)).

Some scholars like Rumenet (1995) say that the stability of human behavior is based on a quasi-stationary equilibrium maintained by a complex field of driving and restraining forces. For change to be accepted, then, the equilibrium needs to be destabilized before old behavior can be discarded (unlearnt), and the future should promise to be better. For others like Lewin (1947a) human's sense of self is defined by one's context of the known and learning. Change, which represents the unknown, then forces to redefine oneself and one's world. Resistance is then a result of this fear. Still others like Gebriel(2002) extrapolate resistance to come from the combination of managerial problems, level of social placement, and vulnerability issues which is the focal interest of this study.

The Ethiopian Civil Service which was formally established during the reign of Menelik II in 1907, underwent a series of structural and strategic changes commensurable with new needs and global imperatives, Getachew H. \& Richard K. (2006). 
The organ which is currently operating as ministry of Capacity Building is practicing change management principles and knowledge in the public organizations. In the recent five years, change is a day to day agenda to almost all public organizations of Ethiopia. Almost all public organizations of the country have tried Business Processing Reengineering (BPR) since 2003, (Tilaye, 2007, \& Yetimgeta, 2007).

While many failed to successfully practice BPR (Tilaye, 2007), the following public organizations were the first successful ones; Commercial Bank of Ethiopia (CBE), Transport Office, Ethiopian Customs and Revenue Authority, Ministry of Trade and Investment, Ministry of Agriculture and Rural Development (Tesfaye, 2009).

Important question that must be posed now is how these organizations were successful to practice BPR. While so many factors can contribute for the failure or success of a change effort, for it is not manageable to exhaust all, resistance to change is separately taken for this study while the Commercial Bank of Ethiopia (CBE) is the population of the study.

The study focuses on identifying the most significant issues that managers leading any change process at any phase should be aware of; meaning to note that which source of resistance at what phase of change presents the highest impact on change effort and determine which aspects should be specially considered at an organizational change.

Then what possible spring points of resistance are there in employees to downpour or secrete confrontation during managerial change effort so that possible counter avoiding can be designed.

\section{Statement of the Problem}

This study follows firmly the three phase model classification of change process of Lewin (1947), which is a well distinguished model by a well known scholarly in the field of management, and takes backups and extrapolations from many other authors whom arguments and principles circle around the Lewin's model.

In this study, all sources of resistance are grouped in to three i.e. demographic attributes of employees driven, personal vulnerability driven as well as managers' incapability driven factors for which their theoretical underpinnings can be seen in the literature review part. The coefficient of all sources of resistance are the critical concerns of this study and are weighed against which aspect of sources of resistance presents a higher disparity of impact considering the phases of the change process. The specific areas that this study assumed need to be empirically investigated are;

- The strength and distribution of vulnerability driven factors of resistance and factors related to the managerial incapability regarding in the Lewin's three phases of the change process (Unfreezing, Moving and Refreezing),

- The significance level of the effect of specific factor under vulnerability driven and the same under managerial incapability driven factors over the phases.

- The existence and distribution of resistance over the demographic attributes of an individual within an organization; how is distributed over age, gender, over experience and educational level, if any.

Resistance to change is a topic of interest for researchers in the field of management and business administration. Pardo et al. (1999), for example, made an empirical study on resistance to change wanted;

$\checkmark$ To observe if resistance is higher in strategic than in evolutionary change and found the more radical and transformational the change is, the more powerful resistance to change is.

$\checkmark \quad$ To know which sources of resistance present a higher disparity considering evolutionary and strategic changes and found the source related to deep rooted values followed by conflict of interests between employees and managers, and the existence of change values that are against organizational values that hinder change are highly inconsistent. 
The Determinants of Resistance to Change Management Process: The Case of CBE, Addis Ababa District

$\checkmark \quad$ To compare the degree of importance of the sources of resistance in general, in evolutionary and in strategic changes, and found that in evolutionary changes the progression of the importance of the sources of resistance is almost the same as in changes in general. Conversely, in strategic changes such hierarchy was found altered. For example, the lack of a creative response was eleventh in general changes and thirteenth in evolutionary changes, but it moved up to the fourth place of importance in strategic changes.

The following paragraphs are some characteristics that set this study apart from the previous researches conducted on the issue. They entail which problems were covered so far and which was not, which specific problem is to be covered now from among the universe of the issue and which is not. .

1. While the above study, Pardo et al. (1999), focuses on the disparity of resistant to changes compared between evolutionary and strategic types of changes, whether the strength of the factors of resistance is similar or not on all the phases of the change process (unfreezing, moving and refreezing), is not on its domain, for which the current study is interested to cover this gap.

2. Even if there are consensuses on the theoretical underpinnings on the relationship between demographic characteristics of an employee and the tendency to resist changes, this study aims at verifying their relationship based on empirical results. This contributes not only on adding new knowledge but also on the confirmation of the existing knowledge if the theories are confirmed.

However, while each resistance variable's statistical significance at different level of the change process (individual, group and organizational level) for the inertia to change are not determined by Pardo et al. (1999), the current study has not also covered it; but believes this perspective is part of the universe of the issue and need to be covered despite the fact that decision is not made to cover this specific problem on this endeavor.

Generally, the need to get depth \& scale in some cases and verify the issues that the scientific community has theoretically agreed on other cases, thereby to reach evidenced conclusion backed by compendium of empirical studies constitute the basis for undertaking this move.

\section{Objectives of the Study}

The main objective of the study is to determine the factors that attribute to the resistance of change management in the Commercial Bank of Ethiopia . Specifically, it aims;

$\checkmark$ To find out the degree of significance of each of the agreed sources of resistance to change with respect to the Kurt Lewin's three phases of change management process

$\checkmark$ To determine whether demographic attributes of an employee like age, gender, education and experience have any significance to resistance to change management

$\checkmark$ To determine the significance level of personal vulnerability on resistance to change management.

\section{Hypothesis of the Study}

The following three debatable points were considered in tradeoff to one another; then which one is declined and which other one accepted are put after the statistical tests.

$\checkmark \quad \mathrm{H}_{1:}$ A single factor of change resistance can have varied significance level on different phases of the Lewin's three phase's model of change process.

$\mathrm{H}_{0}$ : A single factor of change resistance cannot have varied significance level on different phases of the Lewin's three phase's model of change process.

$\checkmark$ H1: Demographic attributes of an employee can significantly cause the tendency to resist an organizational change effort". 
The Determinants of Resistance to Change Management Process: The Case of CBE, Addis Ababa District

$\mathrm{H}_{0}$ : Demographic attributes of an employee cannot significantly cause the tendency to resist an organizational change effort".

$\checkmark \quad \mathrm{H}_{1}$ : Personal vulnerability presents highest significance level on resistance to change throughout all the phases of the change management process.

$\mathrm{H}_{0}$ : Personal vulnerability doesn't presents highest significance level on resistance to change throughout all the phases of the change management process.

\section{Scope of the Study}

This study is conceptually delimited to the determinants of change resistance on selected types of changes that have happened in the Commercial Bank of Ethiopia. Literally, two perspectives, change types and change processes, are the major concepts covered.

From magnitude perspective, resistance on transformational type of change, as many considers BPR to be transformational, eg. Stephen \& Godwin (2010) are covered. But there will always be incremental and major changes as a subset of transformational changes. So, the study also covered these small changes, too. The same is true from focus wise; it is mainly strategic, but operational and evolutionary changes are also there. But resistances according to the level of change, meaning individual, team/unit as well as organizational levels are not seen prospectively.

Hoping to observe a variable factor's significance in different phases of the change process, the Lewin's (1947) three phase's model of change process (unfreezing, moving and refreezing) is exhaustively dealt with.

For reasons to be explained in the methodology part, the study is geographically delimited to the internal environment of the Commercial Bank of Ethiopia in the 27 branches of Addis Ababa; a governmental financial institution in Ethiopia. The study time is confined for the period August 2012 to January 2013. Findings and results of the hypothesis of the research would, therefore, be expected to hold true only for the subjects concerned and for the stated period.

\section{Limitations of the Study}

The study dwells to the unidirectional simple logit regression analysis. While some may expect the simultaneous or bidirectional/ two way/ effects of the dependent and independent variables, for the simultaneous relationship of the variables in this topic would make no sense, the simultaneous model is out of reach of this study.

According to Geoffrey M. et al. (2005), any research has to comply with the following reliability and validity indexes; external, constructive and statistical validity indexes as well as test-retest reliability indexes.

Accordingly, this study lacks, external validity; meaning the results of the study may not generalize to conditions, participants, times, and places other than the stated one.

However, the rest validity indexes are fulfilled in that construct validity is maintained because any question and variable factor indexing element is guided by strong theoretical underpinnings which serve as base for the causal relationship and empirical test of variables.

Statistical validity is also fulfilled in that any aspect of the data quantification and data processing modeling is logit model that is well distinguished in realms of research as a powerful model to analyze a data with a binary categorization.

From reliability angle, this study lacks the Test-Retest reliability in that stability of test scores over time is not known because this action is not repeated on another occasion or time.

Another limitation is that the data is as true as the honesty of the respondents; assumption is respondents will be honest. Besides to this, individual's decision to behave in some way is an amalgamated result of various inner 
processes that no researcher can comprehend and exhaust the inner process rather what is seen is the final decision of the person only, which has unavoidable impact on the accuracy of the study.

Generally, under the unavoidable limitations, using the aforementioned tactics, the study has tried to get data that helps support or reject the established hypothesis.

\section{Significance of the Study}

This study is worth of time, effort and expenses that require priority and urgency of answer. This is because other than other small beneficiaries, the knowledge obtained from this study may serve mainly two major target groups; for the academic world and the business community.

For the academic world, it may contribute to the knowledge of resistance to change from perspectives like the phases of the change process, typology of changes, as well as drivers of resistance by a large compendium of empirical study and different theoretical underpinnings existed separately in discretion forms.

For the business community, it may provide an analytical reflections on which possible source of resistance should be specially considered and which to need customized focus according the phases by showing which concern to increase with what phase, type and level of change it is.

Besides to that, it can be taken as reference for other researchers to conduct deepened research on the topic, or others can refer on the methodology of this study.

\section{LITERATURE REVIEW}

This chapter, by putting the following two major issues to the fore, forms the theoretical framework by wholly basing the theoretical and empirical underpinnings show the relationship.

- The theoretical and empirical backgrounds of the what of change management, its types, and phases and the why of change management

- The theoretical and empirical backgrounds of the what of resistance to change management, the sources to resistance in relation with the phases of the process

\section{Theoretical Backgrounds of Change Management}

Organizational Change management is an important aspect of the discipline management that tries to ensure that a business or any organization of people and asset responds to the environment in which it operates, (Van de Ven and Poole, 1995), by a conscious introduction of new ways of thinking and operating that suit the demand of the changing world for better future (Freese, 1998). Change management occurs when you need to adapt to the environment (Child and Smith, 1987; Leana and Barry, 2000), or when you are dissatisfied with where you are. (Boeker, 1997).

Dealing with change is inescapable.

Change management has got different typologies. Changes can be defined along a continuum starting in magnitude (incremental, major changes and transformational), by Focus of change (strategic or operational), by Level of change (individual, team , organizational), (Bernard ,2004, Strebel,1994), and by phase of change( unfreezing, moving and refreezing), (Kurt lewin, 1947).

\section{In magnitude perspective}

Incremental changes: are small changes that alter certain small aspects, looking for an improvement in the present situation, but keeping the general working framework (Levy, 1986).

Major changes: are substantial changes in an organization and its operations (Nadler and Tushman, 1989). Examples include organizational restructuring, producing new product lines, opening new branches or sites of operation, etc 
The Determinants of Resistance to Change Management Process: The Case of CBE, Addis Ababa District

Transformational changes: are radical changes where the organization completely changes its essential frameworks and values (Ghoshal and Bartlett, 1996), looking generally for a new competitive advantage in the market (Frankwick, 1995) and affecting the core concepts of the organization (Ruiz and Lorenzo, 1999).

\section{From Phases of the change process perspective}

\section{Lewin's Three Phase Theory of change management process}

Kurt Lewin is often cited for his key contribution to organizational change, (Burnes 2004; Rumelt, 1995). A successful change project, Lewin (1947) argued, involved three steps, which is known as the unfreezing-changerefreeze model (Burnes(2004). These are

Stage 1 - Unfreezing

According to Lewin's(1947) argument the stability of human behavior was based on a quasi-stationary equilibrium supported by a complex field of driving and restraining forces. He argued that the equilibrium needs to be destabilized (unfrozen) before old behavior can be discarded (unlearnt) and new behavior successfully adopted. It means getting motivated to change this phase of change is built on the theory that human behavior is established by Past observational learning and cultural influences. Change requires adding new forces for change or removal of some of the existing factors that are at play in perpetuating the behavior. The unfreezing process has three sub-processes that relate to a readiness and motivation to change for proper unfreezing to occur.

Disconfirmation of the validity of the status quo: where present conditions lead to dissatisfaction. However, the larger the gap between what is believed and what needs to be believed for change to occur, the more likely the new information will be ignored.

The induction of guilt or survival anxiety: previous beliefs now being seen as invalid creates "survival anxiety." However, survival anxiety may not be sufficient to prompt change if learning anxiety is present.

Creating psychological safety: learning anxiety triggers defensiveness and resistance due to the pain of having to unlearn what had been previously accepted. Three stages occur in response to learning anxiety: denial; scapegoating \& passing the buck; and maneuvering \& bargaining.

It is necessary to move past the possible anxieties for change to progress. This can be accomplished by either having the survival anxiety be greater than the learning anxiety or, preferably, learning anxiety could be reduced, Schein (1996)

Stage 2 -Changing (Moving)

Once there is sufficient dissatisfaction with the current conditions and a real desire to make some change exists, it is necessary to identify exactly what needs to be changed. Three possible impacts from processing new information are: words take on new or expanded meaning, concepts are interpreted within a broader context, and there is an adjustment in the scale used in evaluating new input.

A concise view of the new state is required to clearly identify the gap between the present state and that being proposed. Activities that aid in making the change include imitation of role models and looking for personalized solutions through trial-and-error learning.

As Schein (1996) , unfreezing creates motivation to learn but does not necessarily control or predict the direction'. This echoes Lewin's view that any attempt to predict or identify a specific outcome from planned change is very difficult because of the complexity of the forces concerned. Instead, one should seek to take into account all the forces at work and identify and evaluate, on a trial and error basis, all the available options (Lewin, 1947). 
Stage 3 - Refreezing

Refreezing is the final stage where new behavior becomes habitual and the change permanent which includes developing a new self-concept \& identity and establishing new interpersonal relationships. It seeks to stabilize the group at a new quasi-stationary equilibrium in order to ensure that the new behaviors are relatively safe from regression. The main point about refreezing is that new behavior must be, to some degree, congruent with the rest of the behavior, personality and environment of the learner or it will simply lead to a new round of disconfirmation (Schein, 1996). This is why Lewin saw successful change as a group activity, because unless group norms and routines are also transformed, changes to individual behavior will not be sustained. In organizational terms, refreezing often requires changes to organizational culture, norms, policies and practices (Cummings and Huse, 1989).

\section{Backgrounds of Resistance to Organizational Change Management}

Different authors have classified sources to resistance from different perspectives.

After wide ranged assessments of the various sources of resistance under different names and angle of looking, this research heavily followed Rumelt (1995), but divides the sources of resistance into three groups. To entertain different perspectives from other authors, other sources of resistance are added to Rumelt's proposal. Some sources of resistance which were treated separately by Rumlet (1995) are mingled with other similar sources and gained another general name. The names of the groups are also altered in order to include the new sources, insights and perspectives.

Accordingly, in this study all the factors of resistance stated by different authors are made to lay under three general factors mainly; demographic attributes driven factors, Vulnerability driven factors or Managerial incapability driven factors.

\section{Theoretical Backgrounds of Resistance to Change Management}

\section{Demographic Attributes Driven Factors}

For reasons not reached or/and covered in this study, individual level characteristics or person oriented issues, which are equally crucial for the success of change (Maria V. et. al (2003) ), have been neglected in many of the scientific studies on organizational change, despite organizational characteristics in change process has been extensively discussed in realms of management literatures. Therefore, the purpose of the present study is to add a different way of looking and working with organizational change by focusing on individuals' demographic attributes, but personal traits are not also failing under the scope of this study despite the fact that they are personal factors. This paper explores how individuals' demographic attributes can hinder or rather facilitate organizational change at an individual level by exploring the relationship between these attributes and attitudes toward organizational change.

After a through revision of literatures, the study has got it more sounding to concentrate on the following employees' demographic attributes as highly pronounced by Rumelt (1995) for the empirical to be detailed under each subsection of the attributes; Age, gender, Educational status and Experience are brought to debate for many scholars on their significance level to resistance to change.

\section{Vulnerability Driven Factors}

According to Marc (2008), change affects the various boundaries within an organization. Boundaries to Mark are the technical, formal and informal structures that an individual will assume in his or her job position and summarized them into three groups. They are;

- Roles (the place a person is assigned in an organization), 
The Determinants of Resistance to Change Management Process: The Case of CBE, Addis Ababa District

- $\quad$ Tasks (is the act required by an individual to work for achieving an output,

- Authority (how the above roles and tasks are authorized, what decision-making authority an individual or group has).

During any change process, the alignment of these boundaries becomes skewed then impacts role, task and authority. Resistance, then, is the way the employees protect themselves from the tilting, operational unfamiliarity, work load and regulatory tightening and the emotions connected to these losses that come from boundary shifts.

As Peter (2007) stated resistance is tied to our belief systems, culture, familiarity in our own and the tension of loosing future general benefits or not meeting our future goal. He assumes that our fear of loss is at the heart of change. Resistance is a result of this fear, an expression of how people feel about the change effort at hand. When things change, people begin to worry about what they might lose, including Job and position, Income and benefits and work place social destructions.

According to William (1980), human's sense of self is defined by his or her roles, his or her responsibilities, and his or her context of the known and learning. Change then forces to redefine oneself and one's world. Change represents the unknown. Change could mean the possibility of failure, the surrender or diminishing of one's span of control and authority or anything of that sort for that matter. Employees do not want to lose the familiar, safe, routine ways of life in favor of the unknown and possibly unsafe area. As humans, one tends to prefer routines and accumulate habits easily since humans behavior which is the function of learning is shaped by rehearsal and usualness. Any one of these possibilities can cause fear, then causing resistance; however, fear of change may be attributed to or can engulf even more than the mere tendency towards regularity or adaptation.

\section{Managerial Incapability Driven Factors}

According to SACD (2000), the factors that can be brought to this category of sources of resistance were;

Knowledge and skills of the leader: change will be resisted if the change agent cannot effect change and does not have the appropriate knowledge and skills to practice, if cannot educate the implementers on what the change is all about, cannot communicate the objectives that should be achieved and if any doubts and questions the population has is not dispelled and answered promptly.

Poor communication (lack of information, misinformation): workers carrying out the change are not informed about the aims of the change; the requirements to introduce the change and how the change will be introduced are not communicated. If incorrect information is given and the usefulness of the change is not well taught.

Organizational climate with low trust: If there is mistrust in the organization

Weak relationships: When relations between the change agent and the employees are not plain

Fear of failure: If they are not sure of the results

\section{Resistance Pertaining to the Phases of Change}

\section{Sources of Resistance in the unfreezing Stage}

The following sources of resistances are the sources that are mainly proposed by Rumnet (1995) but have got many supports from others too. These are taken as a basis to formulate the theoretical framework of the current study but are manipulated in a way that can entertain other way of looking from, for example, listed in the above theoretical and empirical underpinnings. When the frame work is constructed, it has got some sort of new name, general inclusive phrase in a very short way but for now, let directly go to Rumnet's proposal. 
The Determinants of Resistance to Change Management Process: The Case of CBE, Addis Ababa District

\section{Managerial incapability driven factors}

It includes

- Myopia: inability of the company to look into the future with clarity (Rumnet;1995, Barr et al., 1992;

- Communication barriers; information distortion or misinterpretations (Hutt et al., 1995; Rumnet (1995);

- $\quad$ Organizational silence, individuals who do not express their thoughts, meaning (Rumnet, 1995; 2000; Nemeth, 1997).

- $\quad$ Past failures, which leave a pessimistic image for future changes (Rumnet, 1995; Lorenzo, 2000); and

\section{Vulnerability driven factors}

- $\quad$ direct costs of change (Rumelt, 1995)

- $\quad$ cannibalization costs, change that brings success to a product but at the same time brings losses to others,(Rumelt, 1995);

- cross subsidy comforts; because the need for a change is compensated through the high rents obtained without change with another different factor,(Rumelt, 1995);

- Different interests among employees and management; employees value change results less than managers value them (Rumelt, 199; Waddell \& Sohal, 1998).

- $\quad$ complex environmental changes; do not allow a proper situation analysis (Ansoff, 1990; Rumelt, 1995);

\section{Sources of Resistance in the moving phase}

This phase is phase of implementation which is the critical step between the decision to change and state of stability in the new world (Klein and Sorra, 1996). In this stage also, two sources of resistance can be found, mainly;

\section{Vulnerability driven factors}

- Implementation climate; relation between personal change values and organizational values, (Klein and Sorra, 1996; Rumnet, 1995);

- $\quad$ denial ; refusal to accept any information that is not desired (Rumenet, 1995)

- departmental politics or resistance from those departments that will suffer with the change implementation (Rumenet, 1995);

- Incommensurable beliefs; definitive disagreement and conflict among groups of workers about the nature of the problem and its consequent alternative solutions (Klein and Sorra, 1996; Rumelt, 1995);

- $\quad$ Forgetfulness of the social dimension of changes (Lawrence, 1954; Rumelt, 1995).

\section{Change agent's incapability driven factors}

According to Rument, (1995), the factors that fall under this category are;

- Leadership inaction; leaders are afraid of uncertainty

- collective action problems, difficulty to decide who is going to move first,

- $\quad$ Lack of the necessary technical capabilities to implement change - capabilities gap 
Sources of resistance in the refreezing phase

- Perpetuation of ideas; the tendency to go on with the past thoughts even after the situation has changed

- deep rooted values and emotional loyalty

- Inadequate strategic vision, Lack of clear commitment of top management to changes (Rumelt,1995; Waddell and Sohal, 1998).

N.B. Demographic driven factors are not listed in this phase based division because one thing they are not under the proposal of Rumnet (1995) and second thing demographic attributes will not basically change in the phases of change process.

\section{Empirical Backgrounds of Resistance to Change Management}

\section{Vulnerability Driven Factors}

Tesfaye (2009), who made his studies in the then Ethiopian Ministry Of Capacity Building and the then Ethiopian Road Authority about resistance to change reveals that change resistors were due to fear of losing their jobs, while many were waiting to see group that feel indifference about the change, and few tried to protect their friends or subordinates. He also found that the acronym "BPR", the phrase "Result Based Performance Management", and the word "reengineering" were associated with downsizing thereby had become the sources of fear and insecurity for many of the civil service employees. It was also assumed that according to the same author these words are meant for eliminating non-value adding activities, then automating the previous manual activities lead to at least cost reshuffling of employees or downsizing the workers unless the volume of work remained same otherwise.

He further found that assumed that horizontal integration leads to the combination of two or three functional processes into one which resistance was not to abandon their status and benefits while BPR was presumed to cause obsolescence of their knowledge.

Finally, he gave a concluding remark of his research by stating the major causes of resistance are fear of losing position, jobs, benefits, status and obsolescence of skills and knowledge, while he found that resistance of change could come from all managerial levels(lower, middle, and the top level managers.

According to SACD (2000), which made its study in South African companies, the reasons that can be brought to this category of sources of resistance were; Fear of the unknown (uncertainty about causes and effects of the change), Threat to status (Reduction in the size of an organization then to lose their top posts or positions), and threat to power base (reduce the influence one has if resisted by the affected persons).

\section{Managerial Incapability Driven Factors}

According to SACD (2000), which made its study in South African companies, the factors that can be brought to this category of sources of resistance were;

- Knowledge and skills of the leader (if the change agent cannot effect change and does not have the appropriate knowledge and skills to practice, if cannot educate the implementers on what the change is all about, cannot communicate the objectives that should be achieved and if any doubts and questions the population has is not dispelled and answered promptly), change will be resisted.

- Then Poor communication which seems the same with the above but differs in that it concentrates in one, lack of information (workers carrying out the change are not informed about the aims of the change, 
The Determinants of Resistance to Change Management Process: The Case of CBE, Addis Ababa District

the requirements to introduce the change and how the change will be introduced are not communicated. Second, when misinformation (If incorrect information is given and the usefulness of the change is not well taught) happens.

- Organizational climate with low trust: If there is mistrust in the organization,

- Weak relationships: When relations between the change agent and the employees are not plain,

- Fear of failure. If they are not sure of the results,

- Unclear benefits: If the benefits to be gained out of the change are not clear, if there is no any motive to go forward,

- Fear of looking stupid: when the procedures for implementing the change are not well clarified or are unfamiliar to the employees.

According to Beer and Nohria (2000) seventy percent of change efforts fail because of the in capabilities of the top and middle level managers of change mainly; the absence of clear strategy and foreseeable vision, miscommunication and trust, lack of top management commitment, lack of resources needed fully practice the change, lack of managerial skills on change management, and lack of managing resistance to change.

\section{Demographic Attributes Driven Factors}

\section{Age}

According to Bouti (2010), who studied the relationship between employees' age and their resistance to change, by considering organizational tenure as moderators in explaining the age/resistance to change association, a negative relationship between age and the tendency to resist change was found, that implies that younger employees were more resistant to change than older one. He extrapolated his study to find out the behind why of the observation, then stipulated that having a longer work tenure are identified as positive boundary conditions for the observations on the relationship of the two to be opposite.

But according to Maria \& Ioannis (2005), no differences were identified among the four age groups of their samples.

\section{Educational Attainment}

Maria V. etal (2003) studied on the relationship between personal variables and attitudes towards organizational change. To identify whether educational attainment affects employees attitude towards organizational change, he put four levels; basic education, further education degree, university degree, and post graduate degree. Then found that there is a significant effect of educational attainments on resistance to change. In that university graduates express less positive attitudes than both the postgraduate and further education graduates.

But according to Maria and Ioannis 2005), education showed a positive impact on attitudes towards change in that employees with higher education are better equipped to meet new challenges at work then supported their ideas that Iverson (1996) confirms their finding.

\section{Gender}

Maria V. et al (2003), studied on the relationship between personal variables and attitudes towards organizational change. He wanted to examine whether there is significant difference between males and females regarding their attitudes towards organizational change. The result of his study revealed that there was no gender difference regarding attitudes towards organizational change. Sverdlik \& Oreg (2009) also observed no significant difference between men and women in terms of resistance to change management if gender is 


\section{The Determinants of Resistance to Change Management Process: The Case of CBE, Addis Ababa District}

treated independently. But through interaction effect of the combination of gender and experiance, males who had held a position of authority at an earlier employer were less likely to resist change than those who did not fit those criteria (both being male and previous position) .

But according to Maria and Ioannis (2005) aiming to investigate whether gender affects both attitudes to change and stress at work, they conducted independent t-tests and consequently females scored higher than males on attitudes towards organizational change suggesting that males tend to be more reluctant than females toward organizational change. In terms of occupational stress they reported that males also scored significantly higher than females on a number of scales that they used to as indexing; mainly work relationships, overload, and the overall job stress indexes that they believed that change would bring them, demonstrating thus higher levels of occupational stress is found in males compared to females.

Identifying the difference between men and women in change process is also complex since there are feminist men and non feminist women , (Sverdlik and Oreg (2009).

\section{Experience}

According to Sverdlik and Oreg (2009), while all of the demographic variables treated individually have not predicted resistance to change, three interactions (combination) of the variables mainly; gender, faculty experience, and administrative responsibilities at a previous place of employment together negatively predicted the outcome variable (resistance to change), but not until the interaction was observed a significant change.

\section{Theoretical Framework of the Study}

The following sources of resistances are the sources that are extracted from the whole review of literature. The base is Rumnet (1995) but has got many supports from others too. These are taken as a basis to formulate the theoretical framework of the current study but are manipulated in a way that can entertain other way of looking from, for example, listed in the beginning document titled as theoretical and empirical underpinnings. When the frame work is constructed, it has got some sort of new name, general inclusive phrase in a very short way. A summary of this literature review of resistance results in the following sketch of the common view of the concept.

Table2.1. Main Variables

\begin{tabular}{|c|c|}
\hline \multirow[t]{4}{*}{ Demographic attributes driven factors } & Age \\
\hline & Gender \\
\hline & Educational status \\
\hline & Experience \\
\hline \multirow[t]{5}{*}{ Vulnerability driven factors } & Future Work load \\
\hline & Future Job security and position \\
\hline & Future Income and Fringe benefits \\
\hline & Social destruction and operational unfamiliarity \\
\hline & Future Rules and regulations \\
\hline \multirow[t]{6}{*}{ Managerial incapability driven factors } & Myopia/shortsightedness \\
\hline & Interpretation/ communication barriers \\
\hline & Organizational silence/ apathy \\
\hline & Existing investment \\
\hline & past failure and uncertainty anxiety \\
\hline & Implementation capability's gap \\
\hline
\end{tabular}

Source: compiled from literature review 
The Determinants of Resistance to Change Management Process: The Case of CBE, Addis Ababa District

Table2.2. The Variable Relationship

\begin{tabular}{|l|l|}
\hline Independent Variable & Dependent Variable \\
\hline Managerial Incapability Driven Factors & \multirow{2}{*}{ Resistance to organizational change management } \\
\cline { 1 - 1 } Demographic Attributes Driven Factors & \\
\cline { 1 - 2 } Vulnerability Driven Factors Driven Factors & \\
\hline
\end{tabular}

Source: compiled from literature review

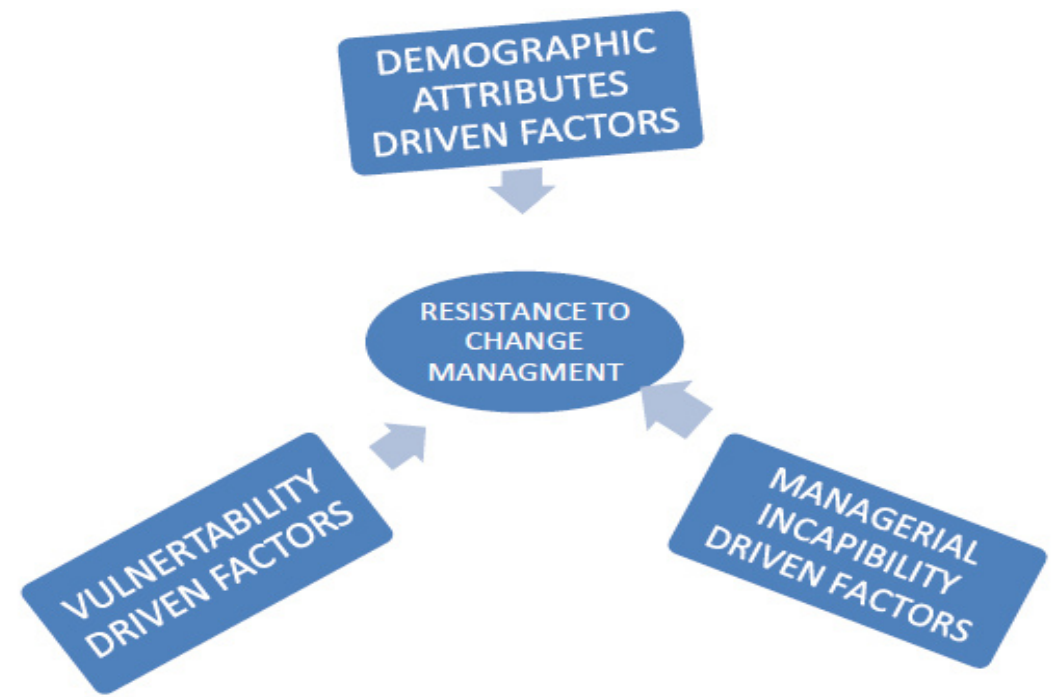

Fig1. A relationship that shows the variable prediction

Source: summary of literatures

After this theoretical exposition, if the sources of resistance resulting from the literature review agree with the ones observed in business practice are checked. Finally, the relationship between sources of resistance in the theoretical framework and the dependent variables are analyzed.

\section{METHODOLOGY}

\section{Research Design}

This research is interested to study the cause and effect relationship of each of the independent variables and the dependent variable on resistance to change. So, apparently, it follows causal research design. A causal type of design suits for this study because it has the following features;

$\checkmark \quad$ It is concerned with describing the causal relationships of the variables

$\checkmark \quad$ It believes that variations in the independent variable will be followed by variations in the dependent variable, when all other things are equal, and so do the hypothesis of the current study.

The study has, therefore, assumed a causal type of research design where the above causational features of the variables can be exhaustively dealt with.

\section{Sample Design}

\section{Target Population}

The population taken for this study is the employees of the Commercial Bank of Ethiopia. It had two criteria for selecting this case. 
As of Levy \& Merry (1986), to make a clear and successful research on resistance, the organization had to be involved in a major or second-order change process. This kind of change processes affects the strategy, structure, hierarchy, culture, technology, and work processes of an organization. It is more likely to find resistance in second-order change processes than in situations where little improvement is sufficient to deal with external demands or to solve internal problems. So, the first criterion for selecting Commercial Bank of Ethiopia (CBE) as a population was due to that the bank has made a second order or major change by BPR.

As of Seashore (1987), an appropriate population to be targeted to work with the feedback method is that the population of the case would be medium-sized (i.e., has 100 to 500 respondents as the author defines medium sized). So, this was the second criterion for selecting the Commercial Bank of Ethiopia as the needed amount of sample can be gained in the bank.

\section{Sample Frame}

For a reason to be explained in the sample size determination, from among the 570 branches of the commercial bank of Ethiopia, 27 branches were taken that are found in Addis Ababa. Selecting Addis Ababa district has the following scientific and cost advantages;

$\checkmark \quad$ Its reputation for better implementation of the reform programs and thereby for better practice of the designed second order change process, as resistance to change process can be better observed in second order changes like strategy, culture, structural, hierarchical, and operational changes, (as of Levy \& Merry (1986)).

$\checkmark$ Due to proximity of branch banks significant time and cost reduction can be achieved.

\section{Sample Size Determination}

According to Miller \& Kunce (1973) and Halinski \& Feldt (1970) as cited by Jamess B. et al. (2001), not to face the risk of over or under fitting in using logit regression analysis, an optimal sample size must consist of ten observations per an independent variable.

Then, theoretically, there are fifteen causing variables for which their variations thought to be followed by variations in the dependent variable of resistance. Their detail is well covered in chapter two of this document.

Thus, taking in to account the idea of the above scholarly people conservatively, the study uses 150 as a sample size of the study which is the multiplied output of ten observations and fifteen independent variables of the study. According to Levy \& Merry (1986), the top level and middle level managers would have better sight of the problems during the change process. Then in the piloted pre data collection, it is found that on average seven respondents can be found in this position. By dividing 150 (the multiplication of ten observations and 15 variables) to seven, it came 22 branches to be approached for data to entertain these ideas of the scholarly.

The concept of sample penalty is dully applied here as some rigidity is required that data from 150 should be collected excluding incomplete answers and unfilled questionnaires. According to Jamess B. et al. (2001), it can be assumed that about 75 percent of the distributed would be collected back correct and therefore in this study it was decided that $25 \%$ more be distributed. Therefore, 200 questionnaires were distributed and the number of bank branches to be approached was raised up to 27 while collection was conducted up to the needed correct amount is gained. Response rate was not determined as collection was stopped after complete 150 was collected.

\section{Sample Selection}

The sampling used is hierarchical; meaning, non probability sampling methods in taking profile but probability sampling to observe a case. This is because according to Levy \& Merry (1986), those who found in higher 
organizational structure of the bank may have better sight of the situation in change process and are better part of the change as it will affect the hierarchy, strategy and role of the position that they work at. But from among the same profile probability sample selection is used.

Code was given to avoid bias on the selection of a case or sample unit. Each sample unit in the population had to get a numerical code according the name fetched from the organization. The numerical code was submitted to excel which case to select then to be produced objectively in lottery method.

\section{Type of Data}

A retrospective dataset but a snapshot from cross section of the population consisting of current single observations on variables at earlier continued points in time was taken. Time is an important dimension in a causal research design and so do the data set taken for this study. It believes that respondents asked at a single point can give reliable retrospective reports of what continuously happened to them or what they thought at some earlier continuous points of time designed in a way of making time series analysis.

Apparently, quantitative type of data was required for the study. But to entertain qualitative ideas, a qualitative questionnaire was designed in such a way that it can be changed in to quantifiable one during analysis so that the data could be processed in inferential statistics. The data taken constituted primary only, as it has something to do with the behavioral science and this study believes that behaviors better be studied primarily in person, not from documents.

\section{Methods of Data Collection}

The research was carried out based on questionnaire distributed to respondents. Respondents had to answer questions dealing with a change process and the tendency to resist that had happened in their respective departments and subordinates. The questions that are expected to allow establish the planned comparison included a list describing the factors that are considered previously as sources of resistance to change. Respondents were asked to give their confirmation or disconfirmation on indirect statements that talk about how much the before-mentioned sources of resistance had affected their tendency to resist. Respondents had to indicate their position among two points on that continuum. Scoring 0 to indirectly talk that it was not a source of resistance at all, and 1 to mean that such source of resistance had contributions to the tendency to resist but not necessarily that it either made the change agents to rethink on the change strategy and process or had slowing effect on implementation. The questionnaire was designed as flexible enough as possible which can allow respondents to include other sources of resistance that was not on the sight of the study with their respective relative impact on the change effort. Unfortunately, however, none of them added another new factor leading to a conclusion that the factors taken were not only appropriate but also complete.

\section{Method of Data Analysis and Statistical Treatment}

\section{Method of Data Analysis}

For the reason that the hub and title of the study is binary categorical in its very nature, applying logit regression model of data analysis seems meaningful and appropriate than other analysis and regression models. A binary dependent variable is a dependent variable whose range of values is substantively restricted to two, zero and one (yes or no), Geoffrey M. et al. (2005). Thus; the study used logit to explain the determinant factors for enhancing change management effort successful or hindering change management efforts. Besides to this, the study used descriptive statistics to describe the sample characteristics.

Descriptive analyses were also used to summarize a study sample and single variable factor prior to analyzing the study's primary hypotheses by amalgamating all sub-variables together. To draw conclusions beyond the immediate samples and data on a single variable, inferential statistics was used in an attempt to draw inferences about the populations from which the samples were drawn as well as about the relative effect of the one variable among others.

American Research Journal of Business and Management Page 15 
The Determinants of Resistance to Change Management Process: The Case of CBE, Addis Ababa District

\section{Statistical Treatment And Modeling}

\section{The Logistic Regression Function}

The binary logit regression modeling used for this study is based on the theoretical backgrounds that resistance is a function of demographic characteristics driven factors, vulnerability driven factors, and managerial incapability driven factors. This is found after so many clash of theories and studies of so many angles then all combined and concluded by the current researcher in the following way. The theories are well covered in chapter two of this document.

The function is;

$R=f(H, M, V)$

Where;

$\mathrm{R}=$ the tendency to resist

$\mathrm{H}=$ Demographic attributes driven factors

$\mathrm{M}=$ Managerial incapability driven factors

$\mathrm{V}=$ Vulnerability driven factors

Then the model is put as follow

The model is; $\operatorname{Logit}(\mathrm{R})=\alpha+\beta_{1} \mathrm{X}_{1}+\beta_{2} \mathrm{X}_{2}+\ldots+\beta_{6} \mathrm{X}_{6}$

$$
\operatorname{logit}[\mathrm{p}(\mathrm{x})]=\log \frac{\mathrm{P}}{1-\mathrm{p}}
$$

Where:

- $\mathbf{X}_{1 \text { to }} \mathbf{x}_{6}$ are the explaining variables,

- $\quad p=$ the probability that a case is in a resistant category, $1-\mathrm{p}=$ the probability not to resist

- The intercept $\alpha$ is the predicted value of $R$ when the $x_{1}$ through $x_{n}$ equal zero when $\left(" x_{i}=\mathbf{0}\right)$ i.e. the disturbance associated with; it contains factors other than $\mathrm{x}_{1}, \mathrm{x}_{2}$ up to $\mathrm{x}_{6}$ that affect $\mathrm{R}$. It is the log odds of a person with zero value of the current explaining variables but to be in the resistant category.

- $\beta_{1}$ is the parameter associated with the predictor variable $\mathrm{x}_{1}$ while $\beta_{2}$ is the parameter associated with the independent variable $\mathrm{x}_{2}$ and so on through $\beta_{6}$ and $\mathrm{x}_{6}$.

Odds Ratio and Marginal Function Analysis

The following section that shows the statistical tools are brought from Geoffrey M. et al. (2005) and Jamess B. et al. (2001)

For a binary event $R$ (i.e. the event either occurs $(R=1)$ or doesn't $(R=0)$ ) let

$\mathrm{P}$ is the $\mathrm{P}(\mathrm{R}=1)$

$\mathrm{P} 1=\mathrm{P}(\mathrm{R}=1 \mid \mathrm{V}=1)$

$\mathrm{P} 0=\mathrm{P}(\mathrm{R}=1 \mid \mathrm{V}=0)$ where

$\mathrm{V}$ is some binary characteristic that is thought to play a role in the conditional distribution of $\mathrm{R}$ (resistance). $\mathrm{V}$ could be gender, vulnerability, managerial incapability, age, education or experience. 
The Determinants of Resistance to Change Management Process: The Case of CBE, Addis Ababa District

One's one of these predictors are found that they have some influence on the probability of the event $\mathrm{R}$ to happen, then these result are presented and interpreted in the following potential parameters of interest:

\section{Computing Odds Ratio From Logistic Regression Coefficient}

\section{Odds}

Odds are ratios defined as the ratio of the probability to its complement, or the ratio of favorable to unfavorable cases. If the probability of an event is a half, the odds are one-to-one or even. If the probability is $1 / 3$, the odds are one- to-two.

$$
\text { Odds }=\frac{p}{1-p}
$$

\section{Log Odds}

Natural $\log$ of the odds are also known as $\operatorname{logit}$. $\log$ odds $=\operatorname{logit}=\operatorname{logit}(\mathrm{p})=\log$. To see this point note that as the probability goes down to zero the odds approach zero and the logit approaches. At the other extreme, as the probability approaches one, the odds approach to and so does the logit. Note that if the probability is $1 / 2$ the odds are even and the logit is zero. Negative logits represent probabilities below one half and positive logits correspond to probabilities above one half. If, for example, there are 30 vulnerable among the 150 respondents, so we estimate the probability as $30 / 150=0.2$. The odds are $30 / 120$ or 0.25 to one, so nonvulnerable outnumber vulnerable by roughly four to one. The logit is $\log (0.25)=-0.602$. In the vulnerable data the estimated logit was -0.602 . Conducting exponentiation on this value one can obtain odds of exp (-0.602) $=$ 0.25 and from this one can obtain a probability of $=0.2$.

\section{Odds Ratio}

The standard way of interpreting a coefficient in logistic regression is using the conversion of it to an odds ratio using the corresponding exp (coefficient) value, Jamess B. et al. (2001). This is ratio of ratios. Odds ratio (OR), estimates the change in the odds of membership in the target group for a one unit increase in the predictor. It is calculated by using the regression coefficient of the predictor as the exponent or exp.

$$
\begin{aligned}
& \text { Odds Ratio }=\frac{\text { odds } 2}{\text { odds } 1}=\frac{\frac{p 1}{1-p 1}}{\frac{p 0}{1-p 0}} \\
& =\quad \underline{\mathrm{P}(\mathrm{R}=1} \mid \underline{\mathrm{V}=1, \mathrm{x})} \\
& 1-\mathrm{P}(\mathrm{R}=1 \mid \underline{\mathrm{V}=1, \mathrm{x})} \\
& \underline{\mathrm{P}(\mathrm{R}=1} \mid \underline{\mathrm{V}=0, \mathrm{x})} \\
& 1-\mathrm{P}(\mathrm{R}=1 \mid \mathrm{V}=0, \mathrm{x})
\end{aligned}
$$

If coefficient is equal to 2.69 , the odds ratio is exp2.69 or 14.73 . Therefore the odds of incorporating is 14.73 times greater for a case, for example, which had a one unit greater value

If the logit $b=1.5$, then the corresponding odds ratio $(\exp (\mathbf{B})$ will be 4.48 . One can then say that when the independent variable increases one unit, the odds that the case can be predicted increase by a factor of around 4.5 times, when other variables are controlled.

A 1 unit increase in education, for example, increases the odds of resistance about 4.5 times.

The idea here is that we want to evaluate everyone's probability of being resistant in two states of the world: when $V=1$ and when $V=0$. One should thus compute $P(R=1 \mid V=1 ; x)$ and $P(R=1 \mid V=0 ; x)$ for each observation in the sample.

Presenting the results of odds ratio in percentage, the decimal number is reported. For instance, if the odds ratio is 1.2 , then one can say on average the vulnerable are 20 percent probable to be incorporated in the 
The Determinants of Resistance to Change Management Process: The Case of CBE, Addis Ababa District

resistant category. It means for a one unit increase or decrease in one variable, we expect to see about 20 percent decrease or increase in the odds of being in the resistant category.

- $\quad$ Coefficient $=\operatorname{Lan} \frac{(p)}{1-p}$

It means, holding other things at a fixed value, what is the odds of getting a resistant category for a person possessing $\mathrm{x}$ variable over the odds of getting in to resistant category for a person not possessing $\mathrm{x}$ variable.

- $\quad \mathbf{M f x}$ (marginal function) = keeping other things constant, what is the probability of a person to incorporate in to resistant category due to one unit increase or decrease of a variable's value from its mean value.

It is the difference of $\mathrm{R}$ occurring for those for whom $\mathrm{V}=1$ over those for whom $\mathrm{V}=0$ for dummy variables and the difference between $\mathrm{V}=\mathrm{x}$ and $\mathrm{V}=\mathrm{x}-1$ or $\mathrm{x}+1$ for continuous variables where $\mathrm{x}$ is the mean):

It is the relative risk of $\mathrm{R}$ occurring for those for whom $\mathrm{V}=1$ over those for whom $\mathrm{V}=0$. It is not the difference in risks. Rather, it is the

\section{Marginal Effects in the Logit}

The marginal effect is the difference in the probability of the event occurring between those for whom $\mathrm{V}=1$ and $\mathrm{V}=0$

The Marginal Effect of $\mathrm{V}$ on the probability of $\mathrm{R}: \mathrm{ME}=\mathrm{p}_{1}-\mathrm{p}_{0}$

$$
=P(R=1 \mid V=1, x)-P(R=1 \mid V=0, x)
$$

\section{Data Presentation And Analysis}

Table4.1. Profile of respondents

\begin{tabular}{|l|l|l|l|}
\hline variable & obs & mean & Std.Dev \\
\hline Age & 150 & 34.97 & 4.10 \\
\hline Education & 150 & 15.89 & 1.30 \\
\hline Experience & 150 & 6.79 & 2.81 \\
\hline
\end{tabular}

Source: primary data produced by stata

It is too hard to exhaustively put the profile of respondents as age, experience, education were put in a continuous way year after year. So to just give a glimpse of the profile, mean value and standard deviation are taken. Accordingly, the mean of the age of the respondents is 34.97 years while on average a single individual's age deviates from this value by 4 Years. Then the mean value of the years of experience of the respondents is 6.79 and the standard deviation of this experience value is 2.8 , while on average an individual respondent has 15.89 numbers of formal educational years. Gender wise, $52 \%$ of the respondents are female.

\section{Assumptions of this analysis}

1. This study assumes that attitudes towards organizational change that will enable a person to decide for accepting or resisting a change is a bi-dimensional construct with a two opposite poles (one positive and one negative). It is in this assumption that the questionnaire is developed.

2. The impact of education for completing one more year of school is considered same no matter which grade year one completes.

3. The impacts of age are considered to give the same per one year older or younger across entire range of ages, no matter which age level.

N.B. These assumptions can be rejected at any time other than this research. 
The Determinants of Resistance to Change Management Process: The Case of CBE, Addis Ababa District

Analysis on the Demographic Attributes Driven Factors of Resistance

To determine the significance level of the general variables that affect the tendency to resists an organizational change effort, a logistic regression analysis was conducted to predict resistance for 150 respondents using vulnerability, managerial incapability and demographic attributes driven factors as predictors. The results of the logistic regression are interpreted using the conversion of it to an odds ratio and marginal functions. Analysis of the odds ratio estimates the change in the odds of membership in the target group (resistant group) for a one unit increase or decrease in the predictor. The marginal function is the difference in the probability of the event occurring between those for whom IV= $\mathrm{x}$ and IV $=\mathrm{x}-1$ for continuous variables and for whom those IV $=1$ and IV= 0 for demy variables.

\section{Education}

Refer Annex 2.1-4 and table 4.2 for detail about the following

To investigate whether educational level affects the tendency to resist or accept a change, logit analysis with conversions of it in to odds ratio and marginal function was performed. The independent variable was the educational attainment counted the number of formal school years and the dependent variable was the tendency to resist while the other predictors were age, experience, managerial incapability, gender and vulnerability.

The marginal function analysis shows that if educational level is increased by one year from its mean value, keeping other things constant, the response probability to resist for a change decreases by .0626887 in the unfreezing phase, by 0.1128887 in the moving phase and by .0438404 in the refreezing phase all in the $\mathrm{p}-$ value lower than the usual threshold of 0.05 (95\% significance). An odds ratio analysis provided that, when other factors are controlled, the odds of getting in to a resistant category for people with lower educational level over the odds of getting in to a resistant category for people with higher educational level is 0.5058056 per one formal school year educational level in the unfreezing, 0.5490948 in the moving and 0.5228659 in the refreezing phase of a change process. In percentage, for a one formal school year increase in education, it is expected to see $51 \%$ decreases in the odds of being in the resistant category in the unfreezing, $55 \%$ in the moving and 53 in the refreezing phases of a change process.

This finding is consistent with the finding of Maria V. et al (2003) who found that there is a significant effect of educational attainments on resistance to change in that university under graduates expressed less positive attitudes than the postgraduate.

It is also consistent with the finding of Maria and Loannis (2005), who even extrapolated their findings by stating employees with higher education are better equipped to meet new challenges at work which is also confirmed by Iverson (1996).

Therefore; it can be tentatively (as an experimental, not explanatory and single study, the findings should be considered tentative until verified by additional research on the why of the relationship) concluded that educational attainment negatively predicts the tendency to resist to an organizational change effort.

\section{Experience}

Refer Annex 2.1-4 and table 4.2 for detail about the following

The marginal function analysis shows that if experience is increased by one year from its mean value, keeping other things constant, the response probability to resist for a change increases by .0321467 in the unfreezing phase, by .045889 in the moving phase and by.0212898 in the refreezing phase all in the p $<0.05(95 \%$ significance).. The odds ratio analysis provided that, holding other factors at a fixed value, the odds of getting in to a resistant category for people with lower experience level over the odds of getting in to a resistant category for people with higher experience is 0.435387 per one year experience level in the unfreezing, 0.382336 in the 
The Determinants of Resistance to Change Management Process: The Case of CBE, Addis Ababa District

moving and 0.432382 in the refreezing phase of a change process. In percentage, for a one year increase in experience, it is expected to see $38.23 \%$ increases in the odds of being in the resistant category in the unfreezing, $43.54 \%$ in the moving and $43.23 \%$ in the refreezing phases.

The finding is consistent with the finding of Maria V. et al (2003) in that they found experience positively predicting the outcome variable. They also extrapolated their finding to the fact that the more the employees have internal experience the more they get a strong quasi-stationary equilibrium of the self maintained by restraining force in a context of the known and learning. They underlined that the equilibrium to be destabilized needs a strong devastating force before old behavior can be discarded (unlearnt), and the days to come should promise to be better; otherwise change which represents the unknown as well as which forces to redefine oneself and one's world would be resisted for granted.

This finding is inconsistent with the finding of Sverdlik and Oreg (2009), in that all of the demographic variables treated individually have not predicted resistance to change in their study. It is also inconsistent because in theirs the three interactions of the variables mainly; gender, faculty experience, and administrative responsibilities at a previous place of employment together negatively predicted the outcome variable (resistance to change), for which predictions are positive in the current study.

For the odds ratio, coefficient and marginal function analysis presented a very strong relationship of the variables in this study, as well as for the interaction effect analysis is not conducted in the current study (it is not statistically valid to compare two different tests), it seems plausible to tentatively conclude that experience positively and strongly predicts resistance by sticking to the current outcome.

Table4.3. Coefficient analysis of the predictors in all of the phases

\begin{tabular}{|c|c|c|c|c|c|c|c|}
\hline \multicolumn{2}{|l|}{ Predictors } & \multirow{2}{*}{$\begin{array}{l}\text { Coef. } \\
-.0799158\end{array}$} & \multirow{2}{*}{\begin{tabular}{|l|} 
Std. Err. \\
.5762905 \\
\end{tabular}} & \multirow{2}{*}{\begin{tabular}{|l}
$\mathrm{Z}$ \\
-0.14 \\
\end{tabular}} & \multirow{2}{*}{\begin{tabular}{|c|}
$P>|z|$ \\
0.890 \\
\end{tabular}} & \multicolumn{2}{|c|}{ [95\% Conf. Interval] } \\
\hline \multirow{7}{*}{$\begin{array}{l}\text { Unfreezing } \\
\text { obs }=150 \\
\text { LR chi2 }(6)=72.49 \\
\text { Prob }>\text { chi2 }=0.0000 \\
\text { Log likelihood }=45.247594 \\
\text { Pseudo R2 }=0.4448\end{array}$} & Gender_1 & & & & & -1.209424 & 1.049593 \\
\hline & Vulnerab 1 & 3.193757 & .7429257 & 4.30 & 0.000 & 1.737649 & 4.649865 \\
\hline & Imanaginc $\sim 1$ & 1.31748 & .5465013 & 2.41 & 0.016 & 2463566 & 2.388602 \\
\hline & Education & -.7048263 & .2574858 & -2.74 & 0.006 & -1.209489 & -.2001634 \\
\hline & Age & .0902853 & .1038507 & 0.87 & 0.385 & -.1132583 & .2938289 \\
\hline & Experience & .3614344 & .1776071 & 2.04 & 0.042 & .0133308 & .709538 \\
\hline & _cons & 2.085881 & 4.961242 & 0.42 & 0.674 & -7.637974 & 11.80974 \\
\hline \multirow{7}{*}{$\begin{array}{l}\text { Moving } \\
\text { obs }=150 \\
\text { LR chi2 }(6)=75.17 \\
\text { Prob }>\text { chi2 }=0.0000 \\
\text { Log likelihood }=53.179678 \\
\text { Pseudo R } 2=0.4141\end{array}$} & Gender_1 & .2008976 & .5106137 & 0.39 & 0.694 & -.7998869 & 1.201682 \\
\hline & Vulnerab 1 & 3.275679 & .6460872 & 5.07 & 0.000 & 2.009371 & 4.541986 \\
\hline & Imanaginc $\sim 1$ & 1.421709 & .6031327 & 2.36 & 0.018 & .2395901 & 2.603827 \\
\hline & Education & -.7964982 & .2298409 & -3.47 & 0.001 & -1.246978 & -.3460183 \\
\hline & Age & -.0732399 & .0922177 & -0.79 & 0.427 & -.2539833 & .1075035 \\
\hline & Experience & .3237748 & .1460756 & 2.22 & 0.027 & .0374719 & .6100778 \\
\hline & _cons & 9.17179 & 4.201067 & 2.18 & 0.029 & .9378503 & 17.40573 \\
\hline \multirow{7}{*}{$\begin{array}{l}\text { Refreezing } \\
\text { obs }=150 \\
\text { LR chi2 }(6)=60.30 \\
\text { Prob }>\text { chi } 2=0.0000 \\
\text { Log likelihood }= \\
-42.052758 \text { Pseudo } \\
\text { R2 }=0.4176\end{array}$} & Gender_1 & .4131202 & .5685308 & 0.73 & 0.467 & -.7011797 & 1.52742 \\
\hline & Vulnerab 1 & 1.43697 & .6080867 & 2.36 & 0.018 & .2451422 & 2.628798 \\
\hline & Imanaginc $\sim 1$ & 3.935963 & .8177563 & 4.81 & 0.000 & 2.33319 & 5.538736 \\
\hline & Education & -.7399578 & .2713833 & -2.73 & 0.006 & -1.271859 & -.2080563 \\
\hline & Age & -.11981 & .1073626 & -1.12 & 0.264 & -.3302368 & .0906167 \\
\hline & Experience & .3593389 & .1797309 & 2.00 & 0.046 & .0070728 & .7116049 \\
\hline & _cons & 8.628381 & 5.00873 & 1.72 & 0.085 & -1.18855 & 18.44531 \\
\hline
\end{tabular}

Source: primary data 
Age

Refer table 4.3 for detail about the following

Hoping to know how resistance to organizational change is distributed over the different age levels of employees, the same analysis was conducted.

The result revealed that the impact of age on the tendency to resist was not statistically significant in all phases and in all $\mathrm{p}$ values $(\mathrm{p}<1 \%, \mathrm{p}<5 \%$ and $\mathrm{p}<10 \%$.)

This is in contrast with the finding of Bouti (2010), who found a negative relationship between age and the tendency to resist change, which implies that younger employees were more resistant to change than older one. He extrapolated his study to find out the behind why of the observations, and then stipulated that having longer work tenure was identified as positive boundary conditions or moderators for the observations on the relationship of the two to be opposite.

But this study is consistent with the findings of Maria and Loannis (2005), as no differences were identified among the four age groups of their samples.

It is possible that the dependence is observed in Bout's finding because Bouti used experience as moderator for that the prediction probability came in age might have come through experience in an invisible root. It may have resulted from the fact that age and experience are conceptually overlapping items, though the items were generated based on different theoretical underpinnings in the literature. But, in here predictors are analyzed independently together. So, without neglecting the findings of Bouti but dedicating to the current one as interaction analysis was not reached seems plausible for that the tendency of age to predict resistance for an organizational change is tentatively not accepted or is declined.

\section{Gender}

Refer table 4.3 for detail about the following

To investigate the distribution of resistance over the male and female groups, coefficient analysis, marginal function and odds ratio analysis methods were conducted. While the results of three of the above presented some gender wise variations with regards to the tendency to resist over the phases, they were reject able in which those values were not statistically significant to predict the tendency in all $p$ values $(p<1 \%, p<5 \%$ and $\mathrm{p}<10 \%$.).

This finding is consistent with the finding of Maria $V$ et al (2003) who found that there was no gender wise varied impact on resistance. Sverdlik and Oreg (2009) also observed no significant difference between men and women in terms of resistance to change management if gender is treated independently. But through interaction effect of the combination of gender and experience, males who had held a position of authority at an earlier employer were less likely to resist change than those who did not fit those criteria (both being male and previous position)

But the current finding is not consistent with the finding of Maria Vakola and Ioannis Nikolaou (2005) who conducted independent $t$-tests and consequently suggesting that males tend to be more reluctant than females toward organizational change.

To get gender predicting resistance Sverdlik and Oreg (2009) conducted interactional effect analysis and Vakola and Ioannis Nikolaou (2005) conducted independent t-test. These tests and analysis were not conducted in here. Statistically it makes sense to dedicate to the type of model used. Therefore, by sticking to the current result of the logit regression analysis, tentatively it is concluded that the dummy variable gender (maleness or femaleness) doesn't predict resistance to an organizational change. 
The Determinants of Resistance to Change Management Process: The Case of CBE, Addis Ababa District

The analysis conducted up to this point helps to consider the alternative hypothesis 2; "Demographic attributes of an employee are significant to the tendency to resist an organizational change effort". This alternative hypothesis is partially accepted as education and experience negatively and positively predicted the tendency to resist a change, respectively. The null hypothesis of it ("Demographic attributes of an employee are not significant to the tendency to resist an organizational change effort".) is also partially accepted because both age and gender independently have not predicted the outcome variable (tendency to resist).

Vulnerability versus managerial incapability driven factors

Odds Ratio and Marginal Function Analysis

Annex 2

The Pearsonian Chi-Square Correlation and Linear Dependence Measure of Variables

\section{ANNEX2.1: Coefficient Wise Logit Result and Odds Ratio in the Unfreezing Phase}

\section{a. Coefficient phase 1}

Iteration 0: $\log$ likelihood $=-81.490917$

Iteration 1: $\log$ likelihood $=-50.638714$

Iteration 2: $\log$ likelihood $=-45.874858$

Iteration 3: $\log$ likelihood $=-45.268845$

Iteration 4: $\log$ likelihood $=-45.247631$

Iteration 5: $\log$ likelihood $=-45.247594$

Logistic regression (

$$
\begin{aligned}
& \text { Number of obs }=150 \\
& \text { LR chi2(6) }=72.49 \\
& \text { Prob }>\text { chi2 }=0.0000
\end{aligned}
$$

Log likelihood $=-45.247594 \quad$ Pseudo R2 $=0.4448$

$$
\text { resistance | Coef. Std. Err. z } \quad \mathrm{P}>|\mathrm{z}| \quad \text { [95\% Conf. Interval] }
$$

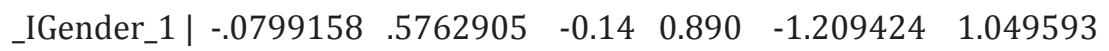

$$
\begin{aligned}
& \begin{array}{llllllll}
\text { _IVulnerab 1| } & 3.193757 & 7429257 & 4.30 & 0.000 & 1.737649 & 4.649865
\end{array} \\
& \begin{array}{lllllll}
\text { _Imanaginc } 1 \mid & 1.31748 & 5465013 & 2.41 & 0.016 & .2463566 & 2.388602
\end{array}
\end{aligned}
$$

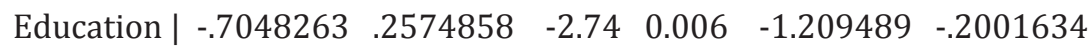

$$
\begin{aligned}
& \text { Age | } \begin{array}{llllll}
0902853 & \text { 1038507 } & 0.87 & 0.385 & -1132583 & .2938289
\end{array} \\
& \begin{array}{lllllll}
\text { Experiance } & \text { 3614344 } & \text { 1776071 } & 2.04 & 0.042 & .0133308 & .709538
\end{array} \\
& \begin{array}{l|llllll}
\text { _cons | } & 2.085881 & 4.961242 & 0.42 & 0.674 & -7.637974 & 11.80974
\end{array}
\end{aligned}
$$


The Determinants of Resistance to Change Management Process: The Case of CBE, Addis Ababa District

\section{b. Odds Ratio Phase 1}

Iteration 0: $\log$ likelihood $=-81.490917$

Iteration 1: $\log$ likelihood $=-50.638714$

Iteration 2: $\log$ likelihood $=-45.874858$

Iteration 3: $\log$ likelihood $=-45.268845$

Iteration 4: $\log$ likelihood $=-45.247631$

Iteration 5: $\log$ likelihood $=-45.247594$

Logistic regression $\quad$ Number of obs $=150$

$$
\begin{aligned}
& \text { LR chi2(6) }=72.49 \\
& \text { Prob }>\text { chi2 }=0.0000
\end{aligned}
$$

Log likelihood $=-45.247594 \quad$ Pseudo R2 $=0.4448$

resistance | Odds Ratio Std. Err. $\quad \mathrm{z} \quad \mathrm{P}>|\mathrm{z}| \quad$ [95\% Conf. Interval]

$\begin{array}{lllllll}\text { _IGender_1 | } & .9231941 & .532028 & -0.14 & 0.890 & .298369 & 2.856488\end{array}$

$\begin{array}{lllllll}\text { _IVulnerab 1 | } & 24.37985 & 18.11242 & 4.30 & 0.000 & 5.683968 & 104.5708\end{array}$

$\begin{array}{lllllll}\text { _Imanaginc } 1 \mid & 3.733998 & 2.040635 & 2.41 & 0.016 & 1.279356 & 10.89825\end{array}$

$\begin{array}{lllllll}\text { Education | } & .4941944 & .127248 & -2.74 & 0.006 & .2983496 & .8185969\end{array}$

Age | $\begin{array}{llllll}1.094487 & 1136632 & 0.87 & 0.385 & .89292 & 1.341554\end{array}$

$\begin{array}{lllllll}\text { Experiance| } & 1.435387 & .254935 & 2.04 & 0.042 & 1.01342 & 2.033052\end{array}$

\section{ANNEX2.2: Coefficient Wise Logit Result and Odds Ratio in the Moving Phases}

\section{a. Coefficient phase 2}

Iteration 0: $\log$ likelihood $=-90.766406$

Iteration 1: $\log$ likelihood $=-57.362338$

Iteration 2: $\log$ likelihood $=-53.548876$

Iteration 3: $\log$ likelihood $=-53.185697$

Iteration 4: $\log$ likelihood $=-53.17968$

Iteration 5: $\log$ likelihood $=-53.179678$

Logistic regression $\quad$ Number of obs $=150$

$$
\text { LR chi2(6) }=75.17
$$$$
\text { Prob }>\text { chi } 2=0.0000
$$

Log likelihood $=-53.179678 \quad$ Pseudo R2 $=0.4141$ 
The Determinants of Resistance to Change Management Process: The Case of CBE, Addis Ababa District

resistance | Coef. Std. Err. $\quad \mathrm{z} \quad \mathrm{P}>|\mathrm{z}| \quad$ [95\% Conf. Interval]

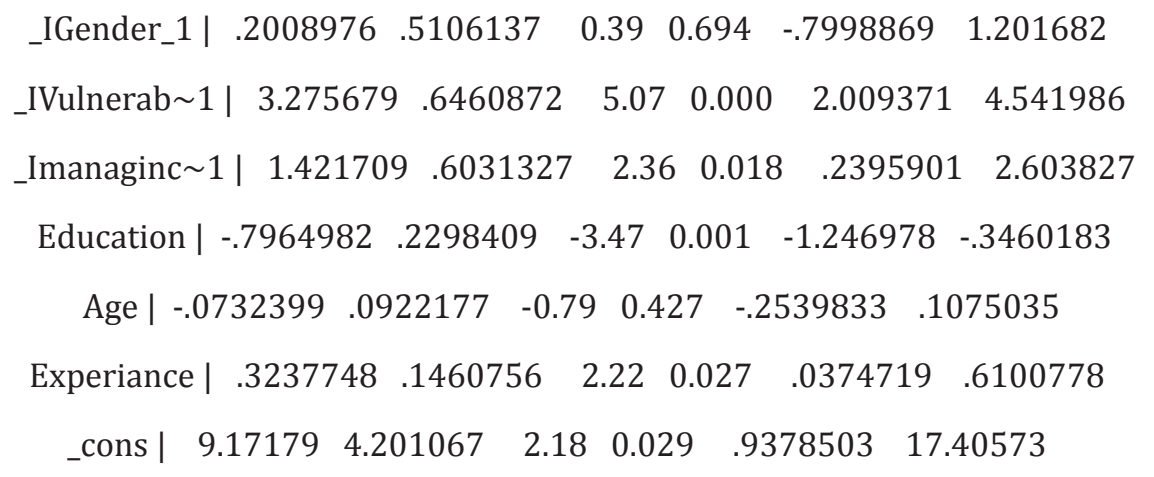

\section{b. Odds Ratio in Phase 2}

Iteration 0: $\log$ likelihood $=-90.766406$

Iteration 1: $\log$ likelihood $=-57.362338$

Iteration 2: $\log$ likelihood $=-53.548876$

Iteration 3: $\log$ likelihood $=-53.185697$

Iteration 4: $\log$ likelihood $=-53.17968$

Iteration 5: $\log$ likelihood $=-53.179678$

Logistic regression $\quad$ Number of obs $=150$

$$
\begin{aligned}
& \text { LR chi2(6) }=75.17 \\
& \text { Prob }>\text { chi2 }=0.0000
\end{aligned}
$$

Log likelihood $=-53.179678 \quad$ Pseudo R2 $=0.4141$

resistance $\mid$ Odds Ratio Std. Err. $\quad z \quad P>|z| \quad$ [95\% Conf. Interval]

$\begin{array}{lllllllll}\text { _IGender_1 | } & 1.2225 & .6242251 & 0.39 & 0.694 & .4493798 & 3.325707 \\ \text { _IVulnerab 1 | } & 26.46118 & 17.09623 & 5.07 & 0.000 & 7.458625 & 93.8771 \\ \text { _Imanaginc 1 | } & 4.144195 & 2.4995 & 2.36 & 0.018 & 1.270728 & 13.51536 \\ \text { Education | } & .4509052 & .1036364 & -3.47 & 0.001 & .2873719 & .7074995 \\ \text { Age | .9293778 } & .0857051 & -0.79 & 0.427 & .7757048 & 1.113495 \\ \text { Experiance | } & 1.382336 & .2019256 & 2.22 & 0.027 & 1.038183 & 1.840575\end{array}$


The Determinants of Resistance to Change Management Process: The Case of CBE, Addis Ababa District

ANNEX2.3: Coefficient Wise Logit Result and Odds Ratio in the Refreezing Phases

a. Coefficient phase 3

Iteration 0: $\log$ likelihood $=-72.203$

Iteration 1: $\log$ likelihood $=-47.853706$

Iteration 2: $\log$ likelihood $=-42.709416$

Iteration 3: $\log$ likelihood $=-42.079849$

Iteration 4: $\log$ likelihood $=-42.052829$

Iteration 5: $\log$ likelihood $=-42.052758$

Logistic regression Number of obs $=150$

LR chi2 $(6)=60.30$

Prob $>$ chi $2=0.0000$

Log likelihood $=-42.052758 \quad$ Pseudo R2 $=0.4176$

resistance | Coef. Std. Err. $\quad \mathrm{z} \quad \mathrm{P}>|\mathrm{z}| \quad$ [95\% Conf. Interval]

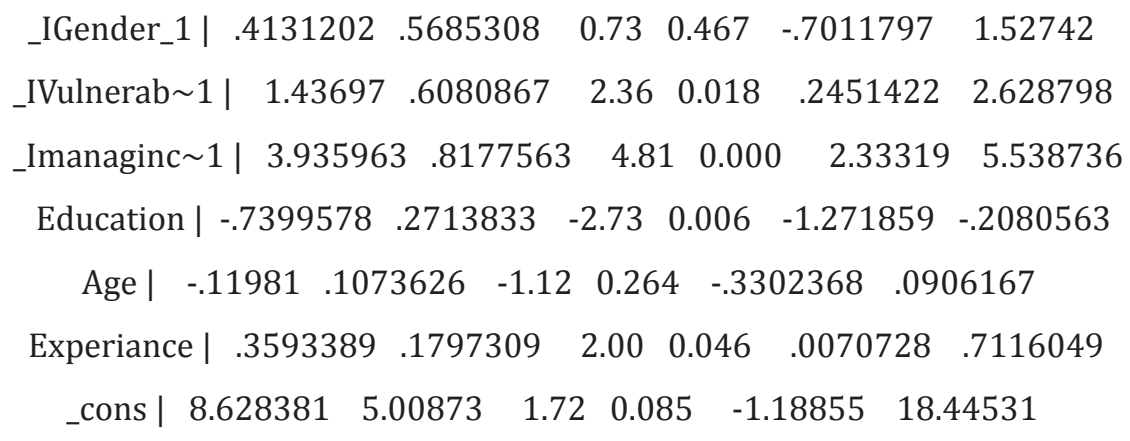

\section{b. Odds Ratio in phase 3}

Iteration 0: $\log$ likelihood $=-72.203$

Iteration 1: $\log$ likelihood $=-47.853706$

Iteration 2: $\log$ likelihood $=-42.709416$

Iteration 3: $\log$ likelihood $=-42.079849$

Iteration 4: $\log$ likelihood $=-42.052829$

Iteration 5: $\log$ likelihood $=-42.052758$

Logistic regression $\quad$ Number of obs $=150$

$$
\begin{aligned}
& \text { LR chi2 }(6)=60.30 \\
& \text { Prob }>\text { chi2 }=0.0000
\end{aligned}
$$

Log likelihood $=-42.052758 \quad$ Pseudo R2 $=0.4176$ 
The Determinants of Resistance to Change Management Process: The Case of CBE, Addis Ababa District

resistance | Odds Ratio Std. Err. $\quad \mathrm{z} \quad \mathrm{P}>|\mathrm{z}| \quad$ [95\% Conf. Interval]

_IGender_1| $1.511527 \quad 8593496 \quad 0.73 \quad 0.467 \quad .4959998 \quad 4.606278$

$\begin{array}{lllllll}\text { _IVulnerab 1| } & 4.207927 & 2.558785 & 2.36 & 0.018 & 1.277803 & 13.85711\end{array}$

_Imanaginc $1 \mid \begin{array}{llllll}51.21144 & 41.87848 & 4.81 & 0.000 & 10.31078 & 254.3562\end{array}$

Education | $\begin{array}{llllll}\text { 4771341 } & \text { 1294862 } & -2.73 & 0.006 & .28031 & .8121613\end{array}$

Age | $\begin{array}{llllll}8870889 & .0952401 & -1.12 & 0.264 & .7187535 & 1.094849\end{array}$

\begin{tabular}{l|llllll} 
Experiance | & 1.432382 & 2574433 & 2.00 & 0.046 & 1.007098 & 2.037258
\end{tabular}

$\left.{ }^{*}\right) \mathrm{dy} / \mathrm{dx}$ is for discrete change of dummy variable from 0 to 1

Table4.2 Marginal Functions of the Predictors in All the Phases

\begin{tabular}{|c|c|c|c|c|c|c|c|c|}
\hline Phases & Predictors & $d y / d x$ & Std. Err. & $\mathrm{z}$ & $\mathrm{P}>|\mathrm{z}|$ & [95\% Conf. & C.I. & Interval] \\
\hline \multirow[t]{6}{*}{ unfreezing } & Gender & -.0071179 & .05132 & -0.14 & 0.890 & -0.107703 & .093467 & 0.52 \\
\hline & Vulnerability & .4790161 & .11565 & 4.14 & 0.000 & .25234 & .705692 & .28 \\
\hline & Managerial incapability & .1426356 & .0742 & 1.92 & 0.055 & -.002787 & .288058 & .333333 \\
\hline & Education & -.0626887 & .02558 & -2.45 & 0.014 & -.112816 & -.012561 & 15.8933 \\
\hline & Age & .0080302 & .00927 & 0.87 & 0.386 & -.010137 & .026197 & 34.9667 \\
\hline & Experience & .0321467 & .01552 & 2.07 & 0.038 & .00172 & .062573 & 6.79333 \\
\hline \multirow[t]{6}{*}{ Moving } & Gender & .0284055 & .07184 & 0.40 & 0.693 & -.112395 & .169206 & .52 \\
\hline & Vulnerability & .5257476 & .09301 & 5.65 & 0.000 & .343446 & .708049 & .426667 \\
\hline & Managerial incapability & .1966289 & .08061 & 2.44 & 0.015 & .038642 & .354616 & .54 \\
\hline & Education & -.1128887 & .03482 & -3.24 & 0.001 & -.181129 & -.044649 & 15.8933 \\
\hline & Age & -.0103804 & .01303 & -0.80 & 0.426 & -.035918 & .015157 & 34.9667 \\
\hline & Experience & .045889 & .02069 & 2.22 & 0.027 & .005334 & .086444 & 6.79333 \\
\hline \multirow[t]{6}{*}{ Refreezing } & Gender & .0244118 & .03418 & 0.71 & 0.475 & -.042588 & .091411 & .52 \\
\hline & Vulnerability & .1053151 & .05667 & 1.86 & 0.063 & -.005749 & .21638 & .366667 \\
\hline & Managerial incapability & .4338297 & .09431 & 4.60 & 0.000 & .248984 & .618675 & .366667 \\
\hline & Education & -.0438404 & .01938 & -2.26 & 0.024 & -.08182 & -.00586 & 15.8933 \\
\hline & Age & -.0070984 & .00632 & -1.12 & 0.262 & -.019489 & .005292 & 34.9667 \\
\hline & Experience & .0212898 & .0107 & 1.99 & 0.047 & .000324 & .042256 & 6.79333 \\
\hline
\end{tabular}

$\left(^{*}\right) \mathrm{dy} / \mathrm{dx}$ is for discrete change of dummy variable from 0 to 1

Source: primary data

That fitted model presented that, holding other things at a fixed value, the odds of getting in to resistant category for vulnerable over the odds of getting in to resistant category for non vulnerable is equal to 24.37985 in unfreezing phase, 26.46118 in moving and 4.207927 in the refreezing phase all in the $p$ - value lower than the upper threshold of 0.05 ( $95 \%$ significance). 
The Determinants of Resistance to Change Management Process: The Case of CBE, Addis Ababa District

Besides to this, the marginal function analysis shows that the probability of getting resistance from the vulnerable people due to a change plan is higher than the probability of getting resistant people from the non vulnerable group of the change plan by .4790161 in the unfreezing, by .5257476 in the moving and by.1053151 in the refreezing.

This result happened at $\mathrm{p}<0.01$ significance level in the first two phases but came down in to $\mathrm{p}<0.05$ in the refreezing phase. The coefficients and significance levels of personal vulnerability driven factors in the first two phases are the highest coefficients and significance levels from the factors studied in this study but managerial incapability driven factors took the position in the refreezing phase at $\mathrm{p}<0.01$ (99\% significance) which was only at $5 \%$ that it was significant in the first two phases.

Therefore, tentatively it can be concluded that resistance that come from personal vulnerability factors are more strong and significant in the plan formulation and implementation phases, then this get reduced during the close up phase and resistance due to the problem that come from managerial incapability gets stronger and more significant at the close up phase of a change process.

In this sense, the alternative hypothesis 1 which says "personal vulnerability presents highest significance level in all the phases of the change process" is rejected or declined. In other words, the null hypothesis of it ("personal vulnerability doesn't present highest significance level in all the phases of the change process") is accepted.

\section{A Single Variable Impact Consistency through the Lewin's Three Phase Model of Change} Process

Table 4.4. Predictor Ranking Through Ratio of the Occurrence $=1$ Given A Predictor Is 1 and Occurrence $=1$ Given A Predictor Is 0 in the Unfreezing Phase; Derived From the Column and Row Statistics of Annex 3

\begin{tabular}{|l|l|l|l|l|l|}
\hline Independent Variable & $\mathrm{fr}(\mathrm{R}=1 \mid \mathrm{IV}=1 ; \mathrm{x})$ & $\mathrm{fr}(\mathrm{R}=1 \mid \mathrm{IV}=0 ; \mathrm{x})$ & $\left.\begin{array}{l}\left(\mathrm{fr}\left(\mathrm{R}=1^{\prime \prime}||^{\prime \prime} \mathrm{IV}=1, \mathrm{x}\right)\right) / \\
\left(\mathrm{fr}\left(\mathrm{R}=1^{\prime \prime}||^{\prime} \mathrm{IV}=0, \mathrm{x}\right)\right.\end{array}\right)$ & $\begin{array}{l}\text { Rank of } \\
\text { ratio }\end{array}$ & Pr \\
\hline Work Load & 20 & 15 & 1.333 & 4 & 0.000 \\
\hline Position & 23 & 12 & 1.925 & 2 & 0.000 \\
\hline Income And Benefits & 19 & 16 & 1.200 & 5 & 0.001 \\
\hline Operational unfamiliarity & 20 & 15 & 1.333 & 4 & 0.023 \\
\hline Job Rules & 18 & 17 & 1.100 & 6 & 0.000 \\
\hline Myopia & 21 & 14 & 1.500 & 3 & 0.000 \\
\hline Communication Barrier & 26 & 9 & 2.900 & 1 & 0.000 \\
\hline Organizational Silence & 19 & 16 & 1.200 & 5 & 0.000 \\
\hline Existing Investment & 26 & 9 & 2.900 & 1 & 0.000 \\
\hline Past Failure & 26 & 9 & 2.900 & 1 & 0.000 \\
\hline Skill Gap & 11 & 24 & 0.800 & 7 & 0.007 \\
\hline
\end{tabular}

Source: primary data

Table 4.5. Predictor Ranking Through Ratio of the Occurrence $=1$ Given A Predictor Is 1 and Occurrence $=1$ Given A Predictor Is 0 in the Moving Phase; Derived From the Column and Row Statistics of Annex 3

\begin{tabular}{|l|l|l|l|l|l|}
\hline Independent Variable & $\operatorname{fr}(\mathrm{R}=1 \mid \mathrm{IV}=1 ; \mathrm{x})$ & $\mathrm{fr}(\mathrm{R}=1 \mid \mathrm{IV}=0 ; \mathrm{x})$ & $\begin{array}{l}\left(\mathrm{fr}\left(\mathrm{R}=1^{\prime \prime} \mid{ }^{\prime \prime} \mathrm{IV}=1, \mathrm{x}\right)\right) / \\
\left(\mathrm{fr}\left(\mathrm{R}=1^{\prime \prime} \mid{ }^{\prime \prime} \mathrm{IV}=0, \mathrm{x}\right)\right)\end{array}$ & $\begin{array}{l}\text { Rank of } \\
\text { ratio }\end{array}$ & $\operatorname{Pr}$ \\
\hline Work Load & 32 & 11 & 2.910 & 4 & 0.000 \\
\hline Position & 34 & 9 & 3.800 & 2 & 0.000 \\
\hline Income And Benefits & 30 & 13 & 2.310 & 7 & 0.000 \\
\hline
\end{tabular}

American Research Journal of Business and Management 
The Determinants of Resistance to Change Management Process: The Case of CBE, Addis Ababa District

\begin{tabular}{|l|l|l|l|l|l|}
\hline \hline Operational Unfamiliarity & 32 & 11 & 2.910 & 4 & 0.000 \\
\hline Job Rules & 26 & 17 & 1.530 & 9 & 0.000 \\
\hline Myopia & 31 & 12 & 2.600 & 6 & 0.000 \\
\hline Communication Barrier & 29 & 14 & 2.100 & 8 & 0.000 \\
\hline Organizational Silence & 33 & 10 & 3.300 & 3 & 0.000 \\
\hline Existing Investment & 31 & 12 & 2.600 & 6 & 0.000 \\
\hline Past Failure & 34 & 9 & 2.800 & 5 & 0.000 \\
\hline Skill Gap & 37 & 6 & 6.211 & 1 & 0.000 \\
\hline
\end{tabular}

Source: primary data

Table 4.6. Predictor Ranking Through Ratio of the Occurrence $=1$ Given A Predictor Is 1 and Occurrence $=1$ Given A Predictor is 0 in the Refreezing Phase; Derived From The Column And Row Statistics of Annex 3

\begin{tabular}{|c|c|c|c|c|c|}
\hline Independent Variable & $\operatorname{fr}(\mathrm{R}=1 \mid \mathrm{IV}=1 ; \mathrm{x})$ & $\mathrm{fr}(\mathrm{R}=1 \mid \mathrm{IV}=0 ; \mathrm{x})$ & $\begin{array}{c}\left(\mathrm{fr}\left(\mathrm{R}=1^{\prime \prime} \mid{ }^{\prime \prime} \mathrm{IV}=1, \mathrm{x}\right)\right) / \\
\left(\mathrm{fr}\left(\mathrm{R}=1^{\prime \prime} \mid{ }^{\prime \prime} \mathrm{IV}=0, \mathrm{x}\right)\right)\end{array}$ & $\begin{array}{c}\text { Rank of } \\
\text { ratio }\end{array}$ & $\operatorname{Pr}$ \\
\hline Work Load & 21 & 7 & 3 & 3 & 0.000 \\
\hline Position & 21 & 7 & 3 & 3 & 0.000 \\
\hline Income And Benefits & 21 & 7 & 3 & 3 & 0.000 \\
\hline Operational Infamiliarity & 13 & 15 & 0.910 & 7 & 0.004 \\
\hline Job Rules & 20 & 8 & 2.500 & 4 & 0.000 \\
\hline Myopia & 23 & 5 & 4.600 & 2 & 0.000 \\
\hline Communication Barrier & 25 & 3 & 8.333 & 1 & 0.000 \\
\hline Organizational Silence & 21 & 7 & 3 & 3 & 0.000 \\
\hline Existing Investment & 17 & 11 & 1.610 & 5 & 0.000 \\
\hline Past Failure & 14 & 14 & 1 & 6 & 0.002 \\
\hline Skill Gap & 21 & 7 & 3 & 3 & 0.000 \\
\hline
\end{tabular}

Source: primary data

This analysis is aimed to observe if resistance is same or not in the three phases of the change process as well as if a single factor has varied impact to resistance over these phases or not. This result makes it fundamental for organizations to identify which source of resistance at which phase deserve special attention to successfully manage resistance for change recurrently.

In so doing, a ratio analysis of the frequency of individuals who are expressed by the predictor and are on the resistant category ( $\mathrm{fr}(\mathrm{R}=1 \mid \mathrm{IV}=1 ; \mathrm{x})$ ) over the frequency of individuals who are expressed by the predictor but not part of the resistant category $\left(\mathrm{fr}(\mathrm{R}=1 \mid \mathrm{IV}=0 ; \mathrm{x})\right.$ ) with a chi ${ }^{2}$ test showing the real significant association of the variables is run distinguishing the three phases of a change process.

As can be observed, every factor that is previously considered to lay in the vulnerability driven or managerial incapability driven indicates that it has had an influence, more or less, (all at p value less than 5\%) and as such the theoretical exposition is supported. The questionnaire also allowed respondents to include other sources of resistance. None of the respondents added any significant factor; so, the list can not only be taken as appropriate but also as complete.

Demographic attributes driven variables are not considered here because these attributes apparently remain same throughout all the phases, more or less. 
Though all the lists that were taken for test were significant(at $p$ value less than 5 percent), no single source was pointed out as the most severe difficulty to achieve the change plan throughout all the phases of the change process; one moves up and the other moves down with the phases.

In the unfreezing phase, the sources of resistance to change with the highest ratio are communication barrier, existing investment and past failure (all with 2.900). It is followed by the fear to lose position (2) and then myopia (1.5). In this phase, change agents' implementation skill gap (0.800) and job rules (1.100) presented the first and second least important factors respectively.

However, in the moving phase such hierarchy is altered; change agents' implementation skill gap moved up to the first place on the list (with a ratio of 6.211) which was the least in the unfreezing phase. Communication barrier, existing investment and past failure which were the first important factors in the unfreezing phase moved down to, more or less, least place of importance in the moving phase $\left(8^{\text {th }}, 6^{\text {th }}, 5^{\text {th }}\right.$ with a ratio of 2.1 , 2.6 and 2.8 all respectively). A similar variation happened with almost all of the rest except of the resistance associated with fear to lose position which remained the same in rank in both phases but with a higher ratio on the second phase (3.800).

Similarly, in the refreezing phase, the source of resistance to change with the highest ratio was communication barrier (8.333), followed by myopia (4.600). A tight job rule which was the least important factor in the moving phase was moved up to $4^{\text {th }}$ in the refreezing phase with 2.5 ratios. In this phase, operational unfamiliarity, past failure and existing investment presented the first, second and third least important factors with a ratio of $0.910,1$, and 1.610 respectively.

The resistance related to losing position came down to third in this phase which was a second in both moving and in the unfreezing phases indicating its important effect and that effect increasing the more at the start up the change phase is.

Communication barrier is also found to be more devastating the more in the plan formulation and closing the change process is.

In this case the guiding alternative hypothesis that says "A single variable factor may have a varied significance level over the three phases of a change process" is accepted.

Likewise, the null hypothesis of it, ("A single variable factor cannot have a varied significance level over the three phases of a change process"), is declined.

\section{CONCLUSION AND RECOMMENDATION}

\section{Conclusions}

The followings are the conclusions drawn.

- Resistance factors significance level present variations considering the phase of change process;

- Vulnerability driven factors present highest significance level for resistance to change in the unfreezing and moving phases of a change process while managerial incapability driven in the refreezing one.

- Educational attainment negatively predicts resistance to organizational change process

- $\quad$ Experience positively predicts resistance to organizational change process

- $\quad$ Age and gender don't predict resistance to organizational change process

\section{From hypothesis perspective;}

The alternative hypothesis, "Demographic attributes of an employee are significant to the tendency to resist an organizational change effort", is partially accepted as education and experience negatively and positively 
The Determinants of Resistance to Change Management Process: The Case of CBE, Addis Ababa District

predicted the tendency to resist a change, respectively. Likewise, the null hypothesis of it, ("Demographic attributes of an employee are not significant to the tendency to resist an organizational change effort".), is partially accepted because both age and gender independently have not predicted the outcome variable (tendency to resist).

The alternative hypothesis that says "A single variable factor may have a varied significance level over the three phases of a change process" is accepted. Likewise, the null hypothesis of it, ("A single variable factor cannot have a varied significance level over the three phases of a change process"), is rejected.

At last the alternative hypothesis which says "personal vulnerability presents highest significance level in all the phases of the change process" is rejected or declined. In other words, the null hypothesis of it ("personal vulnerability doesn't present highest significance level in all the phases of the change process") is accepted.

\section{Recommendation}

It is recommended that an interactional effect analysis of the predictors be conducted to disintegrate overlapping concepts (if any), which was not covered here.

This study restricts itself from prescribing anything to the business world as it considers it is inappropriate to do so before it is verified by another extensive and extended research.

\section{REFERENCES}

1. Ansoff, I.H. (1990): Implanting Strategic Management, Prentice Hall International, Ltd. London

2. Atkilt A. (1996): Civil Service Reform and Administrative Modernisation. Merit: A Quarterly Bulletin of the Ethiopian Civil Service Commission 5, 15-21, Addis Ababa, Ethiopia

3. Barr, P., Stimpert, J. \& Huff, A. (1992): Cognitive Change, Strategic Action, and Organizational Renewal", Strategic Management Journal, 13 (Special Issue), pp. 15-36

4. Beer, Z. and Nohria, B. (2000): Why Change Programs Don't Produce Change; Harvard Business Review, 68 (6), pp. 158-166

5. Belachew Kebede (2011); Analysis Of Bank Service Delivery In Ethiopia, Addis Ababa , Ethiopia

6. Bernard, B. (2004): Kurt Lewin And The Planned Approach To Change: A Re-Appraisal, Manchester, UK

7. Boeker, W. (1997): Strategic change: The influence of managerial characteristics and organizational growth; Academy of Management Journal, 40 (1), pp. 152-170.

8. Bouti, J. (2010); Rethinking resistance and recognizing ambivalence: a multidimensional view of attitudes toward an organizational change", Academy of Management Review, 25 (4), pp. 783-794.

9. Burdett, J. (1999): Leadership in change and the wisdom of a gentleman Participation \& Empowerment; an International Journal, 7 (1), pp. 5-14.

10. Child, J. and Smith, C. (1987); The context and process of organizational transformation - Cadbury Limited in its sector; Journal of Management Studies, 24 (6), pp. 565-593.

11. Commercial Bank of Ethiopia. (CBE)(2010): annual report of the bank of the year 2009/10, page 8-9, Addis Ababa.

12. Cummings, H. \& Huse, P. (1989): Evolution and revolution as organizations grow", Harvard Business Review, (July/Aug.), pp. 37-46.

13. Frankwick, B. (1995): Toward a Definition of Corporate Transformation; Sloan Management Review, 35 (3), pp. 101-106.

American Research Journal of Business and Management

Page 30 
The Determinants of Resistance to Change Management Process: The Case of CBE, Addis Ababa District

14. Freeze, B. (1998): Developing an organization capable of implementing strategy and learning; Human Relations, 49 (5), pp. 597-617.

15. Gebriel A. (2002): Building Civil Service Capacity through Tertiary Level Education: the Ethiopian Experience. Paper presented to the Development Management Institute, Addis Ababa, Ethiopia

16. Geoffrey M. Roben, F. Zuarg, T. (2005): Essentials Of Research Design And Methodology; New Jersy, USA

17. Getachew, H. \& Richard, K. (2006): Civil Service Reform In Ethiopia: Success In Two Ministries Research Memorandum; August 2006, Addis Ababa, Ethiopia

18. Ghoshal, S. \& Bartlett, C. (1996): Rebuilding Behavioral Context: A Blueprint for Corporate Renewal; Sloan Management Review, 37 (2), pp. 23-36.

19. Ghoshal, S. \& Bartlett, C. (1996): Rebuilding Behavioral Context: A Blueprint For Goodstein L.D. , New York, USA

20. Hutt, M., Walker, B. \& Frankwick, G. (1995): Hurdle the Cross-Functional Barriers to Strategic Change; Sloan Management Review, 36 (3), pp. 22-30.

21. Iverson, B. (1996): How to Deal with Resistance to Change; Harvard Business Review, (May/June), pp. 49-57.

22. Jamess, B., Sofger, T. \& John, K. (2001): Organizational Research: Determining Appropriate Sample Size in Survey Research, Muncie, Indiana, the Verge Publisher

23. Kilian, M. Bennebroek, G. (2003); A Different View on Resistance To Change; Paper For "Power Dynamics And Organizational Change IV" Symposium At The 11th EAWOP Conference In Lisbon, Portugal, 14-17 May 2003, Lisbon, Portugal

24. Klein, K. and Sorra, J. (1996): The challenge of innovation implementation; Academy of Management Review, 21 (4), pp. 22-42.

25. Lawrence, P. (1954): How to Deal with Resistance to Change", Harvard Business Review

26. Leana, C. \& Barry, B. (2000): Stability and Change as Simultaneous Experiences in Organizational Life; Academy of Management Review, 25 (4), pp. 753-759.

27. Levy, A. (1986): Second-Order Planned Change: Definition and Conceptualization; Organizational Dynamics, (May), pp. 5-20.

28. Levy, A., \& Merry, U. (1986): Organizational Transformation. Approaches, Strategies, Theories. New York.

29. Lewin, K. (1947): Frontiers In Group Dynamics: Concept, Method And Reality In Social Science; Social Equilibria And Social Change; London Management Review, 25 (4), Pp. 783-794.

30. Lewin, K. (1946): Action research and minority problems; In Lewin, G. W. (Ed.), Resolving Social Conflict. London: Harper \& Row.

31. Lewin, K. (1947a): Frontiers in group dynamics: In Cartwright, D. (Ed.), Field Theory in Social Science. London: Social Science Paperbacks.

32. Lewin, K. (1947b): Group decisions and social change; In Newcomb, T.M. and Hartley, E. L. (Eds), Readings in Social Psychology. New York: Henry Holt.

33. Lorenzo, F. (2000): Structural Inertia and Organizational Change; American Sociological Review, 49, pp. 149-164.

34. Marc, M. \& Frank, B. (1997): Managing Resistance to Change; Hiam, HRD Press. 
The Determinants of Resistance to Change Management Process: The Case of CBE, Addis Ababa District

35. Marc, M.( 2008): Managing Resistance To Change; In TRIAD Consulting Group LLC Ministry Of Capacity Building (2006): Business Process Reengineering Study, Final Report, Addis Ababa.

36. Maria, V., Ioannis, N. \& Suanger, B. (2005): Creating Successful Organization Change; Organizational Dynamics, 19 (4), pp. 5-17.

37. Maria, V., Loannis, N. \& Loannis, T. (2003): The role of emotional intelegnece and personality variables on attitudes towards organizational change; Athens, Greece

38. Mengistu, B. \& Vogel, E. (2006): Bureaucratic Neutrality among Competing Bureaucratic Values in an Ethnic Federalism: The Case of Ethiopia. Public Administration Review Addis Ababa, Ethiopia

39. Miller, D. \& Kunce, T. (1973): Prediction and statistical overkill revisited; Measurement and Evaluation in Guidance, 6(3), 157-163. In Jamess, B., Sofger, T. \& John, K. (2001) Organizational Research: Determining Appropriate Sample Size in Survey Research, Muncie, Indiana, the Verge Publisher

40. Miller, L. \& Smith, K.. (1983): Handling Non response issues. Journal of Extension, 21, 45-50. In Jamess, B., Sofger, T. \& John, K. (2001): Organizational Research: Determining Appropriate Sample Size in Survey Research, Muncie, Indiana, the Verge Publisher

41. Morrison, E. \& Milliken, F. (2000): Organizational Silence: A Barrier To Change Multidimensional View Of Attitudes Toward An Organizational Change", Academy Of Notes Toward A Model Of Managed Learning [WWW Document] (74 Paragraphs). URL Http://Www.Sol-Ne.Org/Res/Wp/10006.Html [2002, March 20].

42. Nadler, D. and Tushman, M. (1990): Beyond the Charismatic Leader: Leadership and Organizational Change; California Management Review, 32 (2), pp. 77-97.

43. Nemeth, C. (1997): Managing innovation: When less is more; California Management Review, 40 (1), pp. 59-74.

44. Paul, L. (2005): How To Deal With Resistance To Change; Belgium, kespi Publisher

45. Peter, S. (2007): Change and Employee Behavior", Leadership \& Organization Development Journal, 19 (3), pp. 157-163.

46. Piderit, S. (2000): Rethinking Resistance And Recognizing Ambivalence: New Delhi, India

47. Ross, A. (2004); Schein's Change Theory, New York, USA

48. Ruiz, G. \& Lorenzo, H. ( 1999); A Far-from-Equilibrium Systems Approach to Resistance to Change; Organizational Dynamics, (Autumn), pp. 16-26.

49. Rumenet, R. (1995): Inertia and transformation; in Montgomery, C.A., Resource-Based and Evolutionary Theories of the Firm, Kluwer Academic Publishers, Massachusetts, pp. 101-132.

50. Schein, E. (1995): Kurt Lewin's Change Theory In The Field And In The Classroom; San Francisco: JosseyBass Publishers.

51. Schein, E. (1999): The Corporate Culture Survival Guide: Sense And Nonsense About Culture Change. San Francisco: Jossey-Bass Publishers.

52. Schuler, D. (2004): Overcoming Resistance To Change: Top Ten Reasons For Chang Resistance, Manchester, UK

53. Seashore, S. (1987): Surveys in Organizations. In J. W. Lorsch (Ed.), Handbook Of Organizational Behavior (Pp. 140-154), Prentice-Hall.

American Research Journal of Business and Management

Page 32 
The Determinants of Resistance to Change Management Process: The Case of CBE, Addis Ababa District

54. Smith, M. (2001): Kurt Lewin: Groups, Experiential Learning And Action Research. [WWW Document]. URL: Http://Www.Infed.Org/Thinkers/Et-Lewin.Htm [2004,September 9].

55. Southern African Development Community (SADC)(200): A Theoretical Framework On Innovations In Education, Canada.

56. Stephen, O. \& Godwin, K. (2010): Business Process Reengineering For Competitive Advantage; Nairobi, AIBUMA Publishing.

57. Strebel, P. (1994): Choosing the right change path; California Management Review, 36 (2), pp. 29-51.

58. Sverdlik, N, \& Oreg, S. (2009): Personal values and conflicting motivational forces in the Context of imposed change. Journal of Personality, 77, 1437-1466.

59. Tesfaye, D. (2009): Business Process Reengineering In Ethiopian Public Organizations: The Relationship Between Theory And Practice, Addis Ababa, Ethiopia

60. Tilaye, K. (2007): Civil Service Reform In Ethiopia: Achievements, Problems And Possible Solutions; The Proceedings Of The First National Conference On The Achievements, Challenges And Prospects Of The Ethiopian Civil Service Reform Program Implementation In Ethiopia. Addis Ababa, Ethiopia May 31, 2007. AddisAbaba. URL:Http:// Www. A2 zpsychology. Com/Articles/ Kurt_Lewin's_Change_Theory.Htm)

61. Tilaye, K. (2010): Rethinking Institutional Excellence In Ethiopia: Adapting And Adopting The Balanced Scorecard (BSC) Model, Addis Ababa, Ethiopia

62. Van de Ven, A. \& Poole, S. (1995): Explaining development and change in Organizations; Academy of Management Review, 20 (3), pp. 510-540.

63. Waddell, D. \& Sohal, A. (1998): Resistance: a constructive tool for change Management; Management Decision, 36 (8), pp. 543-548.

64. Williams, B. (1980): Formal structures and social reality; In D. Gambetta (Ed.), Trust: Making and breaking of cooperative relations (pp. 3-13); Oxford, UK: Blackwell Ltd.

65. Yetimgeta, A. (2007): Approaches To Change Management In The Ethiopian Civil Service: Emphasis On Ethiopian Roads Authority:The Proceedings Of The First National Conference On The Achievements of Civil Service Reform Program Implementation In Ethiopia; May 31-June 1 2007, Addis Ababa, Ethiopia

66. Seashore, S. (1987): Surveys in organizations; In J. W. Lorsch (Ed.), Handbook of Organizational behavior (pp. 140-154). Englewood Cliffs, NY: Prentice-Hall.

67. Levy, A. \& Merry, U. (1986): Organizational transformation. Approaches, strategies, Theories; New York, Praeger.

Citation: Dr. Hiyab Gebretsadik Weldearegay, "The Determinants of Resistance to Change Management Process: The Case of CBE, Addis Ababa District" American Research Journal of Business and Management. 2018; 4(1): 1-33.

Copyright (c) 2018 Dr. Hiyab Gebretsadik Weldearegay. This is an open access article distributed under the Creative Commons Attribution License, which permits unrestricted use, distribution, and reproduction in any medium, provided the original work is properly cited. 